\title{
$s c n 1 b b$, a Zebrafish Ortholog of SCN1B Expressed in Excitable and Nonexcitable Cells, Affects Motor Neuron Axon Morphology and Touch Sensitivity
}

\author{
Amanda J. Fein, ${ }^{1 *}$ Melissa A. Wright, ${ }^{2,3 *}$ Emily A. Slat, ${ }^{1}$ Angeles B. Ribera, ${ }^{2}$ and Lori L. Isom ${ }^{1}$ \\ ${ }^{1}$ Department of Pharmacology, University of Michigan, Ann Arbor, Michigan 48109-0632, and ${ }^{2}$ Department of Physiology and Biophysics, and ${ }^{3}$ Medical \\ Scientist Training Program, University of Colorado Denver at Anschutz Medical Campus, Aurora, Colorado 80045-6511
}

\begin{abstract}
Voltage-gated $\mathrm{Na}^{+}$channels initiate and propagate action potentials in excitable cells. Mammalian $\mathrm{Na}^{+}$channels are composed of one pore-forming $\alpha$-subunit and two $\beta$-subunits. SCN1B encodes the $\mathrm{Na}^{+}$channel $\beta 1$-subunit that modulates channel gating and voltage dependence, regulates channel cell surface expression, and functions as a cell adhesion molecule (CAM). We recently identified scn $1 b a$, a zebrafish ortholog of $S C N 1 B$. Here we report that zebrafish express a second $\beta 1$-like paralog, $s c n 1 b b$. In contrast to the restricted expression of $s c n 1 b a$ mRNA in excitable cells, we detected $s c n 1 b b$ transcripts and protein in several ectodermal derivatives including neurons, glia, the lateral line, peripheral sensory structures, and tissues derived from other germ layers such as the pronephros. As expected for $\beta 1$-subunits, elimination of Scn 1 bb protein in vivo by morpholino knock-down reduced $\mathrm{Na}^{+}$current amplitudes in RohonBeard neurons of zebrafish embryos, consistent with effects observed in heterologous systems. Further, after Scn1bb knock-down, zebrafish embryos displayed defects in Rohon-Beard mediated touch sensitivity, demonstrating the significance of Scn $1 \mathrm{bb}$ modulation of $\mathrm{Na}^{+}$current to organismal behavior. In addition to effects associated with $\mathrm{Na}^{+}$current modulation, Scn1bb knockdown produced phenotypes consistent with CAM functions. In particular, morpholino knock-down led to abnormal development of ventrally projecting spinal neuron axons, defasciculation of the olfactory nerve, and increased hair cell number in the inner ear. We propose that, in addition to modulation of electrical excitability, Scn 1bb plays critical developmental roles by functioning as a CAM in the zebrafish embryonic nervous system.
\end{abstract}

Key words: $\mathrm{Na}^{+}$channel; auxiliary subunit; cell adhesion; electrophysiology; zebrafish; touch sensitivity

\section{Introduction}

In addition to well known ion conduction roles, voltage-gated channels regulate processes as diverse as transcriptional regulation, protein scaffolding, cell adhesion, and intracellular signaling (Dolmetsch, 2003; MacLean et al., 2003; MacLean et al., 2005; Gomez-Ospina et al., 2006; Hegle et al., 2006; Kaczmarek, 2006; Levitan, 2006; Kim et al., 2007; Brackenbury and Isom, 2008; Brackenbury et al., 2008a). In some cases, the latter nontraditional roles of ion channels can occur even in the absence of ion flux. Thus, voltage-gated ion channels have the potential to regulate intercellular and intracellular signaling, and vice versa.

\footnotetext{
Received Sept. 10, 2008; revised 0ct. 6, 2008; accepted 0ct. 9, 2008.

This work was supported by National Institutes of Health (NIH) Grants MH059980 and NS51747 to L.L.I., F31 NS047901 to A.J.F., F30 NS061409 and T32 GM008497 to M.A.W., and NS038937 and NS048154 to A.B.R. A.J.F. was also supported by the University of Michigan Pharmacological Sciences Training Program (NIH Grant $5 T 32$ GM007767). We thank Drs. Matt Voas and William Talbot for their advice on whole-mount immunohistochemistry techniques, Drs. Louis St.-Amant and John Kuwada for their assistance with radiation hybrid mapping, Drs. Yu-Ch Shen and Kate Barald for assistance with inner ear morphology, and Christopher Cooke for expert technical assistance.

${ }^{*}$ A.J.F. and M.A.W. contributed equally to this work and are considered to be co-first authors. Correspondence should be addressed to Lori L. Isom at the above address. E-mail: lisom@umich.edu.

E. A. Slat's present address: Medical Scientist Training Program, Washington University School of Medicine, St Louis, M0 63110.

DOI:10.1523/JNEUROSCI.4329-08.2008

Copyright $\odot 2008$ Society for Neuroscience $\quad$ 0270-6474/08/2812510-13\$15.00/0
}

Voltage-gated $\mathrm{Na}^{+}$channels are traditionally considered to be responsible for initiating and propagating action potentials in excitable cells (Catterall, 2000). Neuronal $\mathrm{Na}^{+}$channels comprise a central, ion-conducting $\alpha$-subunit and two $\beta$-subunits. Although not part of the ion-conducting pore, $\beta$-subunits modulate ion channel gating and voltage dependence and regulate $\mathrm{Na}^{+}$channel cell surface expression. Moreover, $\beta$-subunits possess immunoglobulin superfamily motifs (Isom and Catterall, 1996) and can function as cell adhesion molecules (CAMs), both in the presence and absence of the ion-conducting pore (Isom, 2001). Thus, $\beta$-subunits extend the functional capabilities of $\mathrm{Na}^{+}$channels beyond ion flux.

In vitro, homophilic interactions of $\beta 1$ or $\beta 2$ result in cellular aggregation and ankyrin recruitment (Malhotra et al., 2000, 2002). $\beta 1$ homophilic cell adhesion promotes neurite extension in vitro (Davis et al., 2004) and Scn1b null mice show defective axon extension and fasciculation in vivo (Brackenbury et al., $2008 \mathrm{~b}$ ). Interactions of $\beta 1$ or $\beta 2$ with the extracellular matrix molecule tenascin- $\mathrm{R}$ influence cell migration (Srinivasan et al., 1998; Xiao et al., 1999). $\beta 1$ interacts heterophilically with several other CAMs, including contactin, NrCAM, neurofascin, cadherin, and connexin (Kazarinova-Noyes et al., 2001; Malhotra et al., 2004; McEwen and Isom, 2004; McEwen et al., 2004; Brackenbury et al., 2008b; Brackenbury and Isom, 2008). In vivo, for- 
mation and/or stability of $\mathrm{Na}^{+}$channel signaling complexes at nodes of Ranvier require heterophilic association of $\beta 1$ with contactin (Chen et al., 2004) and $\beta 1$-mediated neurite outgrowth requires both contactin and fyn kinase (Brackenbury et al., 2008b). $\beta$-Subunits also serve as substrates for $\gamma$-secretase and BACE1 in primary neurons, suggesting roles in neuronal development and/or pathophysiology (Kim et al., 2005, 2007; Wong et al., 2005).

We recently cloned the zebrafish gene, scn $1 b a$, encoding a $\beta 1$-subunit that is expressed as two splice variants, scn1ba_tv1 and scn1ba_tv2, but only in excitable cells (Fein et al., 2007). In contrast, expression of the mammalian SCN1B occurs in both traditionally "nonexcitable" tissues as well as excitable cells (Oh and Waxman, 1994, 1995; Diss et al., 2004). On this basis, we hypothesized that zebrafish might express additional SCN1B orthologs. Here, we report the identification of a second $\beta 1$-like paralog, scn $1 b b$, that is not only expressed in excitable tissues but also in the optic nerve myelin sheath, Schwann cells, radial glia, lateral line primordia and neuromasts, olfactory and otic epithelia, and the pronephric duct epithelium. The combined expression patterns of $s c n 1 b a$ and $s c n 1 b b$ resemble that of mammalian $S C N 1 B$, consistent with subfunctional partitioning in teleost duplicated genes. Moreover, morpholino knock-down of Scn1bb protein produces defects consistent with misregulation of $\mathrm{Na}^{+}$ current and cell adhesion, revealing both traditional and nontraditional roles for $\mathrm{Na}^{+}$channel $\beta 1$-subunits in the developing zebrafish nervous system.

\section{Materials and Methods}

Animals. Adult zebrafish (D. rerio) were maintained at the University of Michigan School of Medicine or in the Center for Comparative Medicine at University of Colorado Denver at $28.5^{\circ} \mathrm{C}$ and bred according to established procedures (Westerfield, 1995). Animal protocols were approved by the University of Michigan and the University of Colorado Committees on Use and Care of Animals. The transgenic zebrafish line $\mathrm{Tg}(\mathrm{Hb} 9$ : GFP) was obtained from M. Fox and J. Sanes at Harvard University, Cambridge, MA (Flanagan-Steet et al., 2005).

Cloning. scn $1 b b$ was identified by performing a Blast search for zebrafish sequences with significant homology to the rat $S c n 1 b$ peptide sequence (GenBank AAH94523) (Isom et al., 1992) scn1bb was identified in the EST pool (GenBank EF394326), and the full-length clone was purchased from Open Biosystems. The clone was provided in the pME18S-FL3 vector. The cDNA insert was amplified by polymerase chain reaction using oligonucleotides developed to the pME18S-FL3 vector (5'-CTAGCGGCCGCGACCTGC-3' and 5'-TCATTTTATGTTTCAGGT-3', forward and reverse, respectively) and ligated into the pGEM-T Easy vector (Promega). scn1bb was subsequently excised with NotI and subcloned into the SP64T-BXN vector (Isom et al., 1992) for electrophysiological recording. Construction of a scn8aa vector for oocyte expression was described previously (Fein et al., 2007).

Mapping. scn $1 b b$ was mapped using the LN54 radiation hybrid panel (Marc Ekker, Loeb Institute). PCR was performed using DNA from each of the 93 cell lines or control DNA as template using scnlbb forward ( $5^{\prime}$ ATGGCTCTGAGAACATCATCG- $\left.3^{\prime}\right)$ and reverse (5'-GTGCACGTCTTTACTGGTGACCTT- $3^{\prime}$ ) oligonucleotides. This reaction resulted in the amplification of a $245 \mathrm{bp}$ product corresponding to $s c n 1 b b$. PCR products were analyzed on agarose gels to determine which cell lines were positive for $s c n 1 b b$. Each cell line was scored and the results entered into the LN54 mapping website (http://mgchd1.nichd.nih.gov:8000/zfrh/ß.cgi) which statistically determined the linkage group (LG) for $s c n 1 b b$.

Antibody and toxin labels. Monoclonal anti- $\alpha$-acetylated tubulin and anti-pan- $\mathrm{Na}^{+}$channel antibodies were obtained from Sigma. Polyclonal anti-claudin b was obtained from Dr. A. J. Hudspeth, Rockefeller University, New York, NY. The zn-8 and zrf-1 mouse monoclonals were developed by Dr. B. Trevarrow (Fashena and Westerfield, 1999) and were obtained from the Developmental Studies Hybridoma Bank developed under the auspices of the National Institute of Child Health and Human Development and maintained by the University of Iowa, Department of Biological Sciences. Oregon-Green conjugated phalloidin, Alexa 488 conjugated anti-rabbit IgG and Alexa 594 conjugated anti-mouse IgG were obtained from Invitrogen.

An affinity-purified polyclonal antibody to Scn 1 bb was generated by Open Biosystems as fee-for-service. The peptide sequence of the epitope was: EHYEFSKVTSKD. Anti-Scn 1bb was characterized by Western blot and by immunostaining. Specificity was demonstrated by recognition on Western blots of recombinant $\mathrm{Scn} 1 \mathrm{bb}$ protein expressed in transfected cells (supplemental Fig. $1 A, B$, available at www.jneurosci.org as supplemental material). cDNAs encoding $s c n 1 b b$ or scn1ba (Fein et al., 2007) were subcloned in the pcDNA3.1-Hygro vector (Invitrogen) and used to transiently transfect Chinese hamster lung 1610 cells (Isom et al., 1995). Cells grown to $80 \%$ confluence in $100 \mathrm{~mm}$ dishes were transfected with 8 $\mu \mathrm{g}$ of DNA using Fugene 6 reagent (Roche) according to the manufacturer's instructions and harvested 48 h post-transfection. Mouse brain, rat brain, and zebrafish membranes (from whole fish) were prepared as described (McEwen et al., 2004). Equal aliquots of each protein sample were resuspended in SDS-PAGE sample buffer containing 1\% SDS and $500 \mathrm{~mm} \beta$-mercaptoethanol and heated to $70^{\circ} \mathrm{C}$ for $5 \mathrm{~min}$. Samples were separated on $10 \%$ polyacrylamide SDS-PAGE gels and transferred to nitrocellulose. The Western blot was probed with anti-Scn1bb at a dilution of 1:500 followed by goat anti-rabbit secondary antibody conjugated to HRP (1:2000). Chemiluminescent signals were detected with West Femto reagent (Pierce).

Anti-Scn 1 bb antibody specificity was further determined by blocking the antibody before performing immunohistochemistry with an equivalent volume of immunizing peptide at a concentration of $1 \mathrm{mg} / \mathrm{ml}$ for $1 \mathrm{~h}$ at room temperature. This manipulation abolished the immune signal (supplemental Fig. 1C, available at www.jneurosci.org as supplemental material). Anti-acetylated $\alpha$-tubulin antibody was used as a panneuronal marker in this experiment. Anti-Scn1bb or anti-acetylated $\alpha$-tubulin signals were detected using Alexa 488 conjugated anti-rabbit IgG secondary antibody or Alexa 594 conjugated anti-mouse IgG secondary antibody, respectively.

Immunocytochemistry. Immunocytochemistry was performed on whole mount embryos as described (Woods et al., 2006) or on dissected adult optic nerves as described (Voas et al., 2007). Whole fish were fixed in $4 \%$ paraformaldehyde for $30 \mathrm{~min}$; dissected nerves were fixed for 10 min. Embryos were then washed in standard phosphate buffered saline containing $0.8 \%$ Triton $\mathrm{X}-100$ (PBT), water, and acetone and then blocked in PBT containing 10\% goat serum. Dissected nerves were washed in PBT and then placed directly in the PBT blocking solution containing $10 \%$ goat serum. Anti-Scnlbb (1:500), anti-acetylated $\alpha$-tubulin (1:1000), pan $\mathrm{Na}^{+}$channel (1:500), anti-claudin b (1:250), zn-8 (1:200), or zrf-1 (1:10) antibodies diluted in PBT containing $10 \%$ goat serum, were applied overnight at $4^{\circ} \mathrm{C}$ to either preparation. Phalloidin (Invitrogen) was used at a concentration of 1:40. The following day the embryos and nerves were washed with PBT, and secondary antibody diluted in PBT with 10\% goat serum, was applied. Anti-Scn 1 bb antibody signal was detected using Alexa 488 conjugated anti-rabbit IgG. Zn-8, anti-acetylated $\alpha$-tubulin, or pan- $\mathrm{Na}^{+}$channel antibodies were detected using Alexa 594 conjugated anti-mouse IgG. Embryos and nerves were then washed with PBT and mounted for viewing with an Olympus FluoView 500 confocal microscope located in the University of Michigan Department of Pharmacology. Images were collected with FluoView 4.3 software and analyzed with Adobe Photoshop.

Fish were also cryosectioned $(10 \mu \mathrm{m})$ and stained following standard methods (Chen et al., 2004). Briefly, fish were fixed for $1 \mathrm{~h}$ at room temperature in $4 \%$ paraformaldehyde. They were placed in $30 \%$ sucrose and stored overnight at $4^{\circ} \mathrm{C}$. Fish were then mounted in optimal cutting temperature compound (OCT) on dry ice and stored at $-80^{\circ} \mathrm{C}$ until slicing. Once sectioned, samples were blocked with phosphate buffer $\left(0.02 \mathrm{M} \mathrm{NaH}_{2} \mathrm{PO}_{4}, 0.08 \mathrm{M} \mathrm{Na}_{2} \mathrm{HPO}_{4}\right.$ ) containing $0.3 \%$ Triton X-100 and $10 \%$ normal goat serum. Sections were incubated overnight with antiScn 1 bb antibody (1:500) and anti-acetylated $\alpha$-tubulin antibody (1:2000) at room temperature. Anti-Scn1bb antibody signal was detected using Alexa 488 conjugated anti-rabbit IgG, and anti-acetylated 
$\alpha$-tubulin was detected using Alexa 594 conjugated anti-mouse IgG. Images were collected with a Zeiss Axiophot-2 fluorescent microscope equipped with a Zeiss Axiocam CCD digital camera and Axio Vision software, located in the University of Michigan Microscopy and Image Analysis Laboratory and analyzed with Adobe Photoshop. High magnification images were obtained and analyzed using an Olympus FluoView 500 confocal microscope, FluoView 4.3 software, and Adobe Photoshop.

Electrophysiology. Whole-cell recordings from Rohon-Beard (RB) neurons were obtained in situ as described previously (Ribera and Nüsslein-Volhard, 1998; Pineda et al., 2005). Briefly, $48 \mathrm{hpf}$ embryos were killed in the presence of tricaine and then mounted dorsal side up onto a glass slide. The skin and meninges surrounding the spinal cord were removed. Whole cell patch clamp methods were then used to record $\mathrm{Na}^{+}$currents.

Morpholino injections. Morpholino antisense oligonucleotides (MOs) were synthesized by Gene Tools. The Scnlbb MO (ScnlbbMO1) targeted the predicted translation start methionine of $s c n 1 b b$ and had 25 residues with the following sequence: 5'AGGTGCCGCACACACTCCTGCATGG-3'. A control MO (Scn1bbCTL), with an inverse sequence was also synthesized (5'GGTACGTCCTCACACACGCCGTGGA-3'). Scn1bbCTL injected embryos served as controls. A second translation blocking $\mathrm{MO}$ (5'CGAATGGACGGACAGACGAGCACTC-

$\left.3^{\prime}\right)$, Scn1bbMO2, was also synthesized and yielded similar results to Scn1bbMO1. For simplicity, both translation blocking MOs will be referred to as ScnlbbMO. MOs were injected into the yolk at 1- to 2 -cell at concentrations ranging between 2.5 and $4 \mathrm{ng} / \mathrm{nl}$ in $1 \%$ Fast Green.

Touch sensitivity. To prioritize testing of sensory rather than motor function, we limited our tests of touch insensitivity to embryos that could swim spontaneously with a normal pattern (Pineda et al., 2005). In brief, with a metal probe, we gently touched the dorsal trunk of the embryo. We waited $\sim 3 \mathrm{~s}$ and reapplied the probe for a total of 10 trials. Responses were scored as follows: 0 , no response; 0.5 , nonswimming response (e.g., segmentally restricted trunk bend); 1.0, normal swimming response. The scores of each of the 10 trials were summed to yield final touch response scores between 0 and 10 .

Confocal imaging of morphant phenotypes. Three different phenotypes were analyzed in detail on a Zeiss LSM5 Pascal Confocal Microscope: motor axon morphology, hair cell number, and olfactory nerve branching in the olfactory bulb. To analyze motor axon branching, live $72 \mathrm{hpf}$ $\mathrm{Tg}(\mathrm{Hb} 9: \mathrm{GFP})$ embryos injected with either Scn1bbMO or Scn1bbCTL were mounted laterally between two coverslips in $0.5 \%$ Low Melting Point Agarose dissolved in Embryo Media with Tricaine. Images were collected as z-stacks and projected for analysis. Approximately $600 \mu \mathrm{m}$ of the trunk was imaged in overlapping z-stacks for each embryo, starting with the third segment. Overlapping projected stacks were aligned using Photoshop. Axon branches were traced in Photoshop and counted for each embryo. To measure the (1) number of branches of the olfactory nerve or (2) the number of hair cells in the otic vesicle, embryos were stained for either acetylated $\alpha$-tubulin or actin (using Phalloidin), respectively. Labeled embryos were laterally mounted in $1 \%$ agarose. Images of the olfactory nerve or otic vesicle, respectively, were collected as $\mathrm{z}$-stacks using a $40 \times$ objective. The outline of the olfactory nerve was traced in Photoshop and the number of branches within the olfactory pit was counted. Phalloidin-stained hair cell bundles were counted from projected stacks.
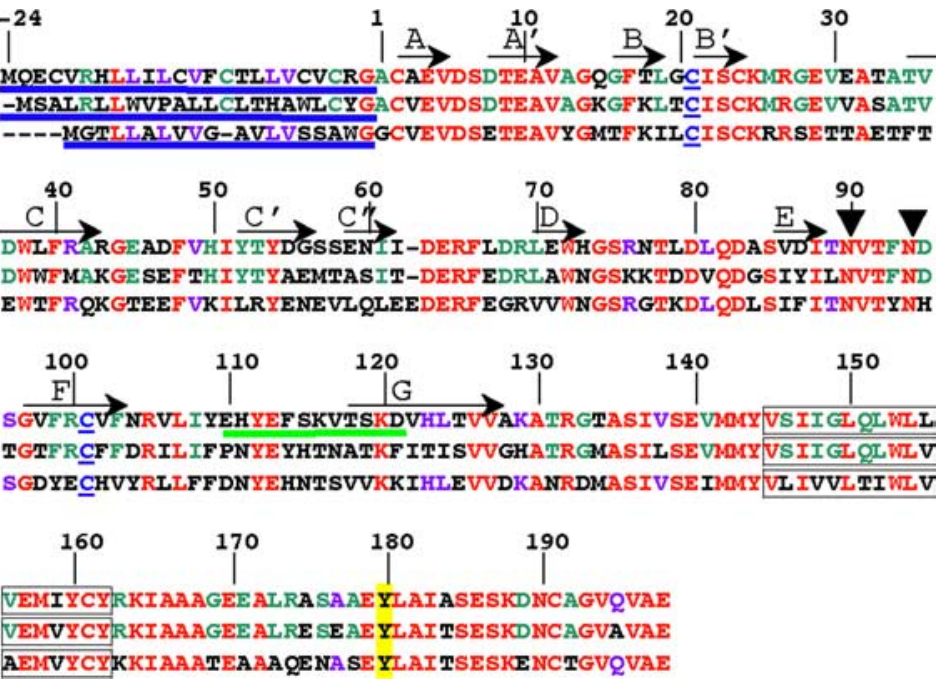

Figure 1. Alignment of $S \mathrm{cn} 1 \mathrm{bb}, \operatorname{Scn} 1 \mathrm{ba}$ _tv1, and $S \mathrm{cn} 1 \mathrm{~b}$. Numbering of the amino acid residues in this figure corresponds to Scesidues that are identical between $S c n 1 b b, S c n 1 b a$, and $S c n 1 b$. Residues in purple are residues that Al spanning segments are indicated as boxed residues. The tyrosine residue, Y-180, homologous to Y-181 in Scn1b (Malhotra et al., 2004) is highlighted in yellow. The peptide sequence used for anti-Scn1bb antibody production is underlined in green.

\section{Results}

\section{Zebrafish scn1bb is homologous to $\mathrm{Scn} 1 \mathrm{~b}$ and $\operatorname{sen} 1 \mathrm{ba}$}

We identified a second SCN1B ortholog in zebrafish, $s c n 1 b b$ (according to the zebrafish nomenclature convention: http://zfin.org/zf_info/nomen.html) that encodes the protein Scnlbb. Alignment of zebrafish Scn 1 bb with rat Scn 1 b shows that the two $\beta 1$-subunit proteins share $51 \%$ amino acid identity (Fig. 1, residues in red), with an additional $16 \%$ of residues that are strongly similar, and $11 \%$ of residues that have weak similarity. The previously isolated zebrafish $\beta 1$-like ortholog, $s c n 1 b a$, predicts a protein that shares $65 \%$ identity with Scn 1 bb (Fig. 1, residues in green) (Chopra et al., 2007; Fein et al., 2007).

The Scn 1 bb sequence contains an N-terminal signal peptide followed by the start of the mature protein at residue A-25 (Fig. 1, signal peptides underlined in blue) corresponding to the experimentally confirmed site in Scn 1 b (Isom et al., 1992). The amino acid sequences of the three zebrafish $\beta 1$-like subunits predict a single transmembrane domain (Fig. 1, boxed residues). Similar to Scn1ba (Fein et al., 2007), Scn1bb contains two conserved cysteine residues that are predicted to form an extracellular Ig loop domain (Fig. 1, cysteines in blue and underlined) (McCormick et al., 1998). Examination of the predicted $\beta$ sheets of the extracellular Ig loop domain reveals that the residues that lie along the A/A' face, a known site of interaction with the $\alpha$-subunit in mammals, are highly conserved in the zebrafish $\beta 1$ paralogs (McCormick et al., 1998).

Similar to Scn1ba, Scn1bb contains a conserved tyrosine at position 180 (Fig. 1, yellow highlight) that corresponds to tyrosine-181 in Scn1b. This tyrosine has been shown to be important for recruitment of ankyrin, Scn 1b subcellular localization, and Scn 1b-mediated channel modulation in vitro (Malhotra et al., 2002, 2004). In contrast to the 4 predicted N-linked glycosylation sites in mammalian Scn1b or zebrafish Scn1ba, Scn1bb 
contains only two N-linked glycosylation sites (Fig. 1, N-90 and N-94, arrowheads; NetNGlyc 1.0 - http://www.cbs.dtu.dk), a feature that may result in different effects of each Scn 1 b paralog on modulation of gating of various $\mathrm{Na}^{+}$channel $\alpha$-subunits (Johnson et al., 2004).

\section{Map position of scn $1 \mathrm{bb}$}

Identification of the $s c n 1 b b$ gene in combination with the previous isolation of $s c n 1 b a$ reveals that zebrafish has two genes that are orthologous to the single mammalian SCNB1 gene. Zebrafish $s c n 1 b b$ and the previously identified scnlba show high sequence similarity, as expected for duplicated genes. Duplicated genes can arise in tandem and reside near each other. Alternatively, duplicated genes, especially in teleosts, can arise by large scale genome duplication. To determine the origins of the multiple SCNB1 orthologs in zebrafish, we first determined whether $s c n 1 b b$ resides near $s c n 1 b a$, as expected for tandem duplication events, or on another linkage group (LG), consistent with large scale genome duplication. We mapped the position of scn1bb to LG19. The best overall marker linked to $s c n 1 b b$ was Z4379 with a logarithm of the odds (lod) score of 20.1, positioning scn $1 b b 2.84 \mathrm{cR}$ from Z4379 (http://mgchd1.nichd.nih.gov:8000/zfrh/ $\beta$.cgi). In contrast, scn1ba mapped to LG16 (Fein et al., 2007). Interestingly, LG16 and LG19 have been shown to be a duplicate chromosomal pair, based on analysis of the gene content of these two chromosomes (Woods et al., 2005), supporting the possibility that $s c n 1 b a$ and $s c n 1 b b$ are duplicates arising from a genome-wide duplication event.

If $s c n 1 b a$ and $s c n 1 b b$ were duplicates, we would expect these genes to be orthologous to and show synteny with the same mammalian gene $(S c n 1 b)$. A high degree of synteny exists between scn1ba and mouse Scn1b (Fein et al., 2007). We did not observe synteny between $s c n 1 b b$ and $S c n 1 b$. However, chromosomal rearrangements occur during evolution that can obscure the original syntenic relationships between genes (Postlethwait, 2007). On this basis, we named the new $\beta 1$-like subunit gene $s c n 1 b b$ to reflect its high similarity to its presumed duplicate, scnlba.

\section{Scn 1 bb protein expression in central and peripheral glia}

We previously reported expression of $s c n 1 b a$, the gene duplicate of $s c n 1 b b$, throughout the retina and optic nerve (Fein et al., 2007). On this basis, we determined the localization of Scn 1 bb in the retina and optic nerve at $5 \mathrm{dpf}$ in $10 \mu \mathrm{m}$ cryo-sections. In contrast to Scn1ba, we observed no retinal expression of Scn 1 bb. Interestingly, the only significant anti-Scnlbb staining in this region appeared in cells that surrounded the optic nerve (Fig. $2 A-C)$. As expected, anti-acetylated $\alpha$-tubulin strongly labeled optic nerve axons and some retinal layers but not cells surrounding the optic nerve (Fig. 2 B, ON) (Fein et al., 2007). The merged image showed no overlap between the expression patterns of the two proteins (Fig. 2C).

We next compared the localization of Scn 1 bb to that of voltage-gated $\mathrm{Na}^{+}$channels in isolated optic nerves. $\mathrm{Na}^{+}$channels localize in high density clusters at nodes of Ranvier in central and peripheral myelinated axons in mammals (Girault and Peles, 2002; Kazarinova-Noyes and Shrager, 2002) and have been detected in the zebrafish posterior lateral line (PLL) nerve (Woods et al., 2006). In isolated adult optic nerve preparations, we observed anti-Scn 1 bb labeled cells wrapping the optic nerve axons (Fig. $2 D, F)$. In contrast, pan- $\mathrm{Na}^{+}$channel $\alpha$-subunit antibody labeled optic nerve axons on which high density clusters (arrowheads), possibly developing hemi-nodes, were evident (Fig. $2 E, F)$. In the merged image, Scn 1 bb immunoreactivity was lim- ited to the myelinating glial processes in the optic nerve and was absent from the axons (Fig. $2 \mathrm{~F}$ ). Importantly, $\mathrm{Na}^{+}$channel $\alpha$-subunit immunoreactivity was absent from the oligodendrocyte processes wrapping the axons, suggesting that $\mathrm{Scn} 1 \mathrm{bb}$ is expressed independently of the $\alpha$-subunit and plays a nonconducting role in the myelin sheath.

We also observed expression of Scn 1 bb in the spinal cord of 72 hpf larvae. Anti-Scn1bb labeled a network of cells with parallel processes at regular intervals (Fig. $2 G$ ). These Scn1bb positive cells were negative for two different neuronal markers, zn8 and $\alpha$-tubulin staining (Fig. 2G, data not shown) (Fashena and Westerfield, 1999). The Scn1bb immunopositive cells extended long radial processes dorsally, as previously described for radial glia (Fig. 2G) (Lewis and Eisen, 2003). In addition, peripheral Schwann cells showed Scn1bb immunoreactivity (Fig. 2 H, I, arrows). The identification of the Scn 1 bb immunopositive cells in the periphery as Schwann cells was made on the basis of their location surrounding peripheral motor nerves (Fig. $2 \mathrm{H}, \mathrm{I}$ ) and positive immunoreactivity for $\mathrm{zrf}-1$, an antibody that recognizes the glial marker, glial fibrillary associated protein (Fig. 2 I). Interestingly, not all of the Scn 1 bb signal in Figure $2 I$ is positive for zrf-1, raising the possibility that Scn1bb may be expressed in other cells that ensheath motor nerves, e.g., perineurial glia $(\mathrm{Ku}-$ cenas et al., 2008).

\section{Scn1bb protein localizes to lateral line structures}

The lateral line system in zebrafish mediates behaviors involved in predator avoidance and courtship. The lateral line system consists of nerves and external mechanosensory organs, called neuromasts, that are responsive to changes in water movement (Whitfield, 2005). Several characteristics of the lateral line made it an attractive system to investigate with respect to Scn 1 bb. First, the lateral line system consists of both excitable as well as nonexcitable cells. Second, the development of the lateral line system requires interactions among the different cell types, a process that likely involves CAM function.

We first determined whether Scn 1 bb was expressed early during lateral line development. During formation of the lateral line in the trunk (PLL), neuromasts are deposited by migration of two different primordia, known as prim I and prim II. Prim I migration occurs between 20 and $42 \mathrm{hpf}$. As prim I migrates posteriorly, it deposits discrete groups of cells, proneuromasts, along the horizontal myoseptum across the full length of the trunk. Sensory axons of the octavolateralis system closely follow this migration (Sapède et al., 2002; López-Schier et al., 2004). We detected Scn 1 bb immunoreactivity in prim I in $28 \mathrm{hpf}$ embryos, during early stages of the migration process (Fig. 3A). At this time, prim I did not express the neural marker, acetylated $\alpha$-tubulin, but the trailing axon did (Fig. 3A, long arrow).

At relatively much later stages (3-7 dpf), prim II migrates posteriorly and deposits the secondary neuromasts, thus forming the remainder of the mature posterior lateral line (Sapède et al., 2002). At 5 dpf, prim II expressed Scn 1 bb (Fig. 3B). In addition, Scn 1 bb localized to newly deposited neuromasts trailing the primordium (Fig. 3B, arrowheads). At this early stage, the neuromasts were not yet labeled by anti-acetylated $\alpha$-tubulin, although innervating neurites were labeled (Fig. $3 B$, long arrow). In contrast, claudin $b$ is expressed in migrating primordial cells similar to Scn1bb (López-Schier et al., 2004). We observed no overlap between anti-claudin b labeling in prim II and the trailing neurites labeled by anti-acetylated $\alpha$-tubulin (Fig. $3 C$ ). These results indicate that Scn $1 \mathrm{bb}$ is present during the early stages of PLL migration similar to claudin $b$. 


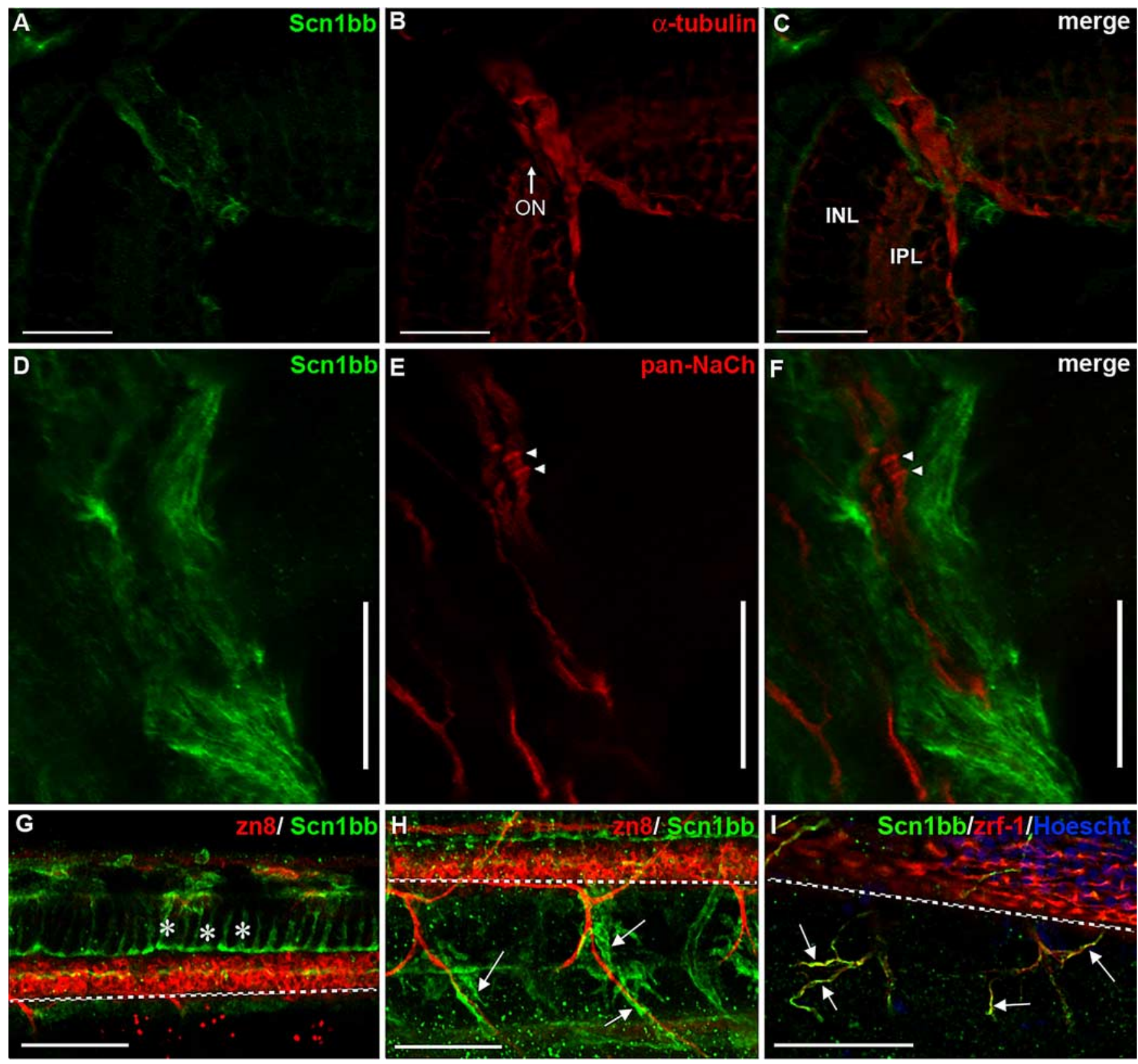

Figure 2. Scn1bb is expressed in optic nerve and spinal cord glia. $A-C$, Cryosections; scale bars, $25 \mu \mathrm{m}$. $A$, At 5 dpf, the retina displays little or no Scn 1 bb immunoreactivity (green). However, cells surrounding the optic nerve $(0 \mathrm{~N})$ are strongly $S \mathrm{cn} 1 \mathrm{bb}$ immunopositive. $\boldsymbol{B}$, Acetylated $\alpha$-tubulin (red) staining is observed in layers of the retina (e.g., inner plexiform layer, IPL) and strongly labels the optic nerve (ON). $\boldsymbol{C}$, The merged image of $\boldsymbol{A}$ and $\boldsymbol{B}$ demonstrates that $\operatorname{Sen} 1 \mathrm{bb}$ (green) and acetylated $\alpha$-tubulin (red) immunoreactivites do not overlap in the optic nerve. In addition, the $S \mathrm{cn} 1 \mathrm{bb}$ signal surrounds that of the neuronal marker acetylated $\alpha$-tubulin, indicating that $S \mathrm{cn} 1 \mathrm{bb}$ immunopositive cells localize to the location of optic nerve myelin. $\boldsymbol{D}-\boldsymbol{F}$, Dissected optic nerves; $s$ cale bars, $10 \mu \mathrm{m}$. D, We detected strong Scn1bb immunoreactivity in optic nerves dissected from adult zebrafish. $\boldsymbol{E}$, In addition to $\mathrm{Scn} 1 \mathrm{bb}$, isolated adult optic nerves display axonal expression of pan-Na channel $\alpha$-subunits ( $\mathrm{NaCh}$, red). $\mathrm{Na}^{+}$channel $\alpha$-subunit clusters, possibly hemi-nodes, are indicated with arrowheads. $\boldsymbol{F}$, The merged image shows that $\mathrm{Scn} 1 \mathrm{bb}$ (green) and $\mathrm{Na}{ }^{+}$channel $\alpha$-subunit (red) immunoreactivities are nonoverlapping, consistent with Scn $1 \mathrm{bb}$ expression in the myelinating glia that ensheath the retinal ganglion cell axons within the optic nerve. $G-I$, Lateral view of whole mount $72 \mathrm{hpf}$ embryos, anterior to the left, dorsal at the top. Scale bars, $50 \mu \mathrm{m}$. The dashed white line indicates the ventral boundary of the spinal cord. $\mathbf{G}$, Radial glia (asterisks) in the spinal cord express $S \mathrm{cn} 1 \mathrm{bb}$ (green) and can be identified by their characteristic elongated morphology, stretching from the dorsal spinal cord to just above the secondary motor neurons (labeled with zn8, red). $\boldsymbol{H}$, Scn1bb-positive cells (green, arrows) surround, but do not overlap with, ventral motor neuron axons (labeled with zn8, red). I, Scn1bb (green) colocalizes with the Schwann cell marker zrf-1 (red), suggesting $S \mathrm{cn} 1 \mathrm{bb}$ is expressed in Schwann cells (arrows) that ensheath peripheral motor axons.

In addition to the PLL, zebrafish also have an anterior lateral line system. At $5 \mathrm{dpf}$, anti-Scn 1 bb labeled each neuromast in the anterior lateral line (Fig. 3D, arrowheads). PLL neuromasts were similarly labeled at this stage (Fig. 3E). In neuromasts, antiacetylated $\alpha$-tubulin identifies hair cell somata as well as the kinocilia projecting from the neuromast hair cell bundle (Raible and Kruse, 2000; López-Schier et al., 2004). Although acetylated $\alpha$-tubulin and Scn 1 bb expression were detected in the same neu- romast (Fig. 3D-F), the two expression patterns were nonoverlapping. Rather than labeling the kinocilia of the hair cells, as did anti-acetylated $\alpha$-tubulin, anti-Scn 1 bb labeled the supporting cells found at the base of the neuromast (Fig. $3 F$ ).

\section{Scn 1bb protein expression in the olfactory system}

Similar to the lateral line, the zebrafish olfactory system develops early and consists of many different cell types (Hansen and 

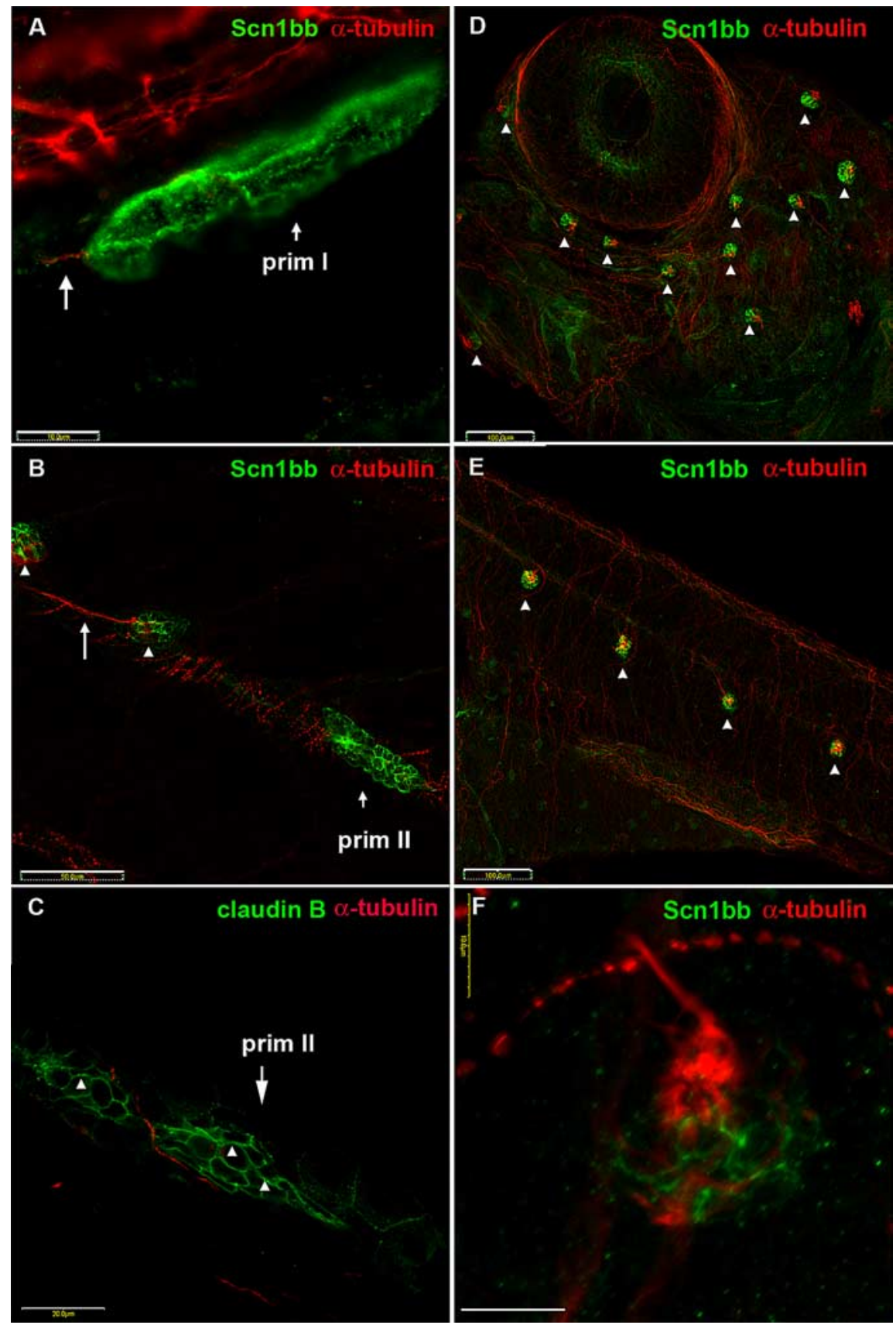

Figure 3. Scn1bb is expressed in migrating primordia and neuromasts of the lateral line system. $\boldsymbol{A}-\boldsymbol{C}$, Migrating primordia and newly formed neuromasts express $S c h n 1 b b$ protein. $\boldsymbol{A}$, Immunocytochemistry reveals nonoverlapping expression of both $S c n 1 b b$ (green) and acetylated $\alpha$-tubulin (red) proteins in the migrating prim I lateral line primordium of $28 \mathrm{hpf}$ embryos. The octavolateralis system axons (long arrow), that trail prim I, display acetylated $\alpha$-tubulin immunoreactivity. Scale bar, $10 \mu \mathrm{m} . \boldsymbol{B}$, In $5 \mathrm{dpf}$ larvae, the prim II lateral line primordium and newly deposited neuromasts express Scn1bb (green). However, prim II (short arrow) and newly deposited neuromasts (arrowheads) do not express acetylated $\alpha$-tubulin. In contrast, an innervating neurite (long arrow) is positive for acetylated $\alpha$-tubulin immunoreactivity. Scale bar, $50 \mu \mathrm{m}$. C, Similar to Scn1bb, claudin b (arrowheads) is present in prim II in a complementary pattern to anti-acetylated $\alpha$-tubulin. Scale bar, $50 \mu \mathrm{m}$. D-F, ALL and PLL neuromasts express $S c n 1 b b$ protein. $\boldsymbol{D}$, In $5 \mathrm{dpf}$ embryos, anti-Scn $1 \mathrm{bb}$ (green) specifically reveals neuromasts of the ALL (arrowheads). Scn1bb and acetylated $\alpha$-tubulin (red) are expressed in different domains of the ALL neuromasts. Anti-acetylated $\alpha$-tubulin marks the kinocilia of ALL neuromasts. Scale bar, $100 \mu \mathrm{m}$. $\boldsymbol{E}$, In $5 \mathrm{dpf}$ embryos, anti-Scn $1 \mathrm{bb}$ (green) also is present within the neuromasts of the PLL (arrowheads). Similar to the ALL, Scn1bb and acetylated $\alpha$-tubulin (red) are expressed in different domains of the PLL neuromasts. Scale bar, $100 \mu \mathrm{m}$. $\boldsymbol{F}$, Different cell types within a neuromast express $\mathrm{Scn} 1 \mathrm{bb}$ (green) and acetylated $\alpha$-tubulin (red). Supporting cells display $\operatorname{Scn} 1 \mathrm{bb}$ immunoreactivity, whereas hair cells express acetylated $\alpha$-tubulin (red) in the soma and projecting kinocilia. Scale bar, $10 \mu \mathrm{m}$.
Zeiske, 1993). We observed expression of Scn 1 bb in the olfactory pits at $5 \mathrm{dpf}$ in addition to lateral line neuromasts (Fig. $4 A$; OP indicates olfactory pits; arrowheads indicate neuromasts). Anti-acetylated $\alpha$-tubulin labeled cilia projecting from olfactory sensory neurons (OSNs) as well as the kinocilia of the intervening supporting cells, as shown previously (Tsujikawa and Malicki, 2004). Glia-like olfactory supporting cells, also called sustentacular cells (Hegg and Lucero, 2006), are arranged in a ring at the rim of the olfactory pit, interspersed with ciliated OSN dendritic knobs, resulting in a dense fringe of acetylated $\alpha$-tubulin-positive cilia (Fig. 4B) (Hansen and Zeiske, 1993). Merging of these two images showed that Scn $1 \mathrm{bb}$ and acetylated $\alpha$-tubulin do not colocalize and that expression of Scn $1 \mathrm{bb}$ is limited to the supporting cells (Fig. 4C).

At higher magnification, Scn1bb protein was evident in the supporting cell somata but absent from the cilia and the OSN dendritic knobs (Fig. 4D). In contrast, anti-acetylated $\alpha$-tubulin showed strong labeling of the outward projecting cilia and weak labeling in the OSN dendritic knobs (Fig. $4 E$, arrows). In the merged image, expression of Scn1bb was observed interspersed between the OSN dendritic knobs, in close apposition to, but not overlapping with, the expression domain of acetylated $\alpha$-tubulin (Fig. $4 F$ ).

\section{Non-neuronal cells of the inner ear cells} also express $\mathrm{Scn} 1 \mathrm{bb}$ protein

The zebrafish inner ear sensory system develops early, has multiple cell types and shares structural and functional similarity with the lateral line (Nicolson, 2005). At 5 dpf, we detected Scn 1 bb immunoreactivity in the epithelial pillars (ep) around which the semicircular canals form (Fig. $5 A$ ). This was in contrast to the expression of acetylated $\alpha$-tubulin in the kinocilia of the surrounding sensory regions including the anterior macula $(\mathrm{am})$, posterior macula $(\mathrm{pm})$ and posterior cristae (pc) (Fig. $5 B$ ). Merging the two staining patterns revealed nonoverlapping expression of Scn 1 bb and acetylated $\alpha$-tubulin in inner ear (Fig. 5C). In addition to the epithelial pillars of the inner ear, anti-Scn1bb also labeled the supporting cells at the base of one of the otic neuromasts (Fig. 5D, arrowhead) (Raible and Kruse, 2000). In agreement with our previous findings (Fig. 3 ), acetylated $\alpha$-tubulin labeled the kinocilia projecting from the center of the neuromast (Fig. 5E, arrowhead), and its expression was nonoverlapping with $\mathrm{Scn} 1 \mathrm{bb}$ (Fig. $5 F$ ). Scn 1 bb immunoreactivity did 


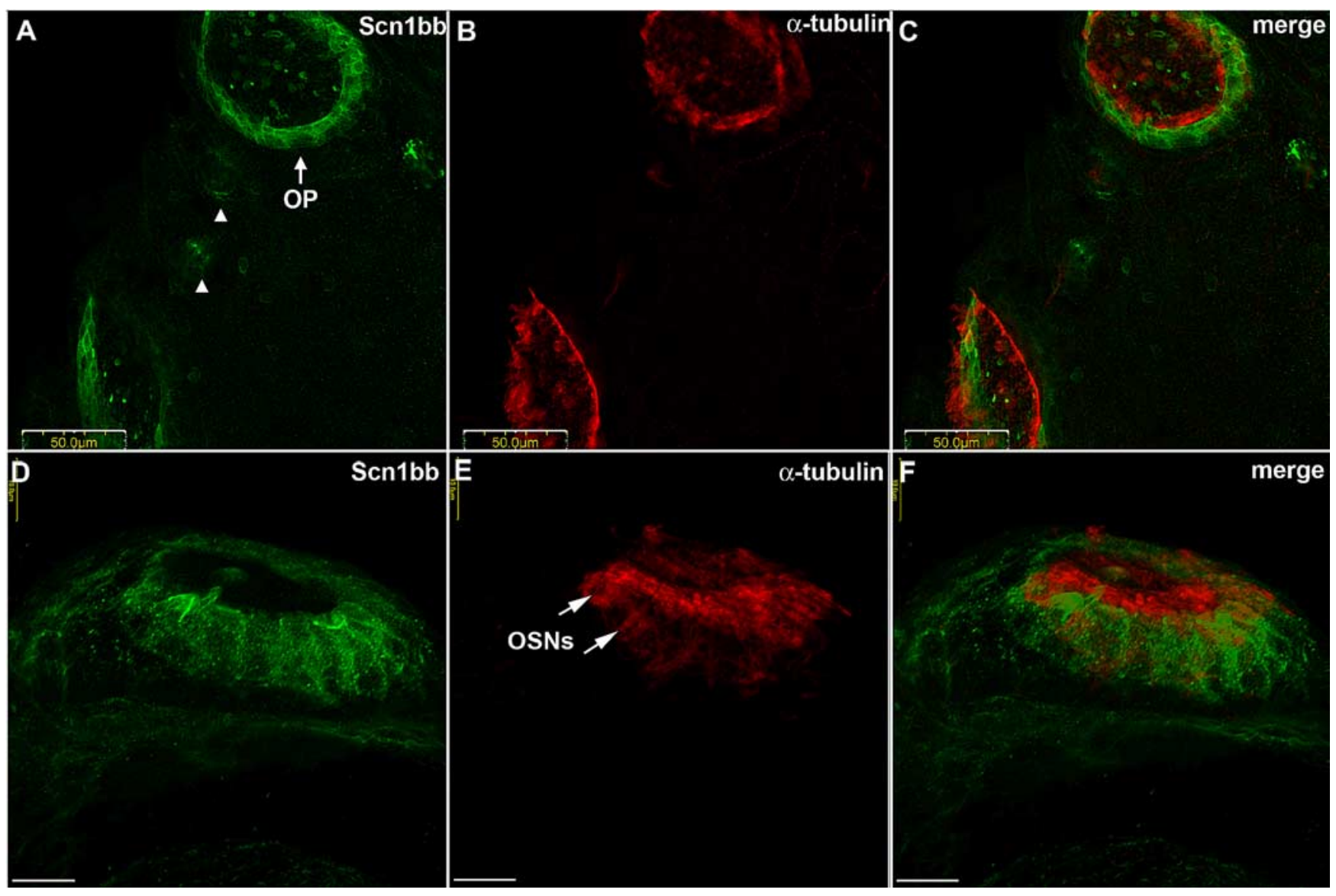

Figure 4. $S \mathrm{cn} 1 \mathrm{bb}$ is expressed in the supporting cell bodies of the olfactory pits. $A$, Anti-Scn1bb (green) labels a ring of cell bodies in the olfactory pits (OP) and the intervening neuromasts (arrowheads) in fish that are $5 \mathrm{dpf}$. B, Anti-acetylated $\alpha$-tubulin (red) labels olfactory pits in a ring corresponding to cilia and kinocilia. $\boldsymbol{C}$, Merged image showing that anti-Scn $1 \mathrm{bb}$ (green) and anti-acetylated $\alpha$-tubulin (red) staining are nonoverlapping. $\boldsymbol{D}$, High magnification image of a side view of an olfactory pit shows $\operatorname{Scn} 1 \mathrm{bb}$ (green) expression in the supporting cell bodies. $\boldsymbol{E}$, Anti-acetylated $\alpha$-tubulin (red) stains the layer of kinocilia projecting from supporting cells and ciliated OSN dendritic knobs (arrows). $\boldsymbol{F}$, Nonoverlapping expression of $S \mathrm{cn} 1 \mathrm{bb}$ (green) in the supporting cell bodies and acetylated $\alpha$-tubulin (red) in the kinocilia, cilia, and OSN dendritic knobs. Scale bars: $A-C, 50 \mu \mathrm{m} ; \boldsymbol{D}-\boldsymbol{F}, 10 \mu \mathrm{m}$.

not overlap with another neuronal marker, zn-8 (Fig. 5G-I). Together, the data indicate that $S \mathrm{cn} 1 \mathrm{bb}$ localizes to non-neuronal cells in neuromasts of the inner ear.

\section{Scn 1 bb protein localizes to epithelia in the developing kidney} In light of Scn1bb's expression pattern in non-neuronal ciliated cells within sensory structures, we tested whether Scnlbb was expressed in other non-neuronal ciliated cells. Our initial in situ hybridization studies (supplemental Fig. 2, available at www. jneurosci.org as supplemental material) revealed $s c n 1 b b$ mRNA in the embryonic kidney, or pronephros, an organ composed of ciliated cells. Similar to lateral line neuromasts, the pronephric ducts form from tissue deposits laid by migrating primordia (Drummond et al., 1998). The ducts comprise polarized epithelial cells that are lined with cilia. Formation of the ducts is completed by $24 \mathrm{hpf}$ (Drummond, 2003, 2005). At $28 \mathrm{hpf}$, the pronephros contained Scn 1 bb protein within the duct (Fig. $6 \mathrm{~A}$, arrow). Anti-acetylated $\alpha$-tubulin labeled the cilia lining the length of the ducts, as demonstrated previously (Fig. 6B) (Drummond, 2005). When we examined the pronephric duct at higher magnification at the point where the duct reaches the cloaca, we observed that anti-Scn1bb labeled the epithelial cells that line the duct (Fig. $6 D)$, whereas anti-acetylated $\alpha$-tubulin labeled the ciliated interior of the duct (Fig. 6E). As in the lateral line and inner ear, expression of the two proteins was nonoverlapping (Fig. $6 F$ ). At even higher magnification, it was evident that Scn 1 bb is ubiqui- tously present in the epithelial cells (Fig. 6G), whereas acetylated $\alpha$-tubulin is expressed in the cilia projecting from these cells (Fig. $6 \mathrm{H})$. The expression patterns of the two proteins are in close apposition, but nonoverlapping in the pronephros (Fig. 6I).

\section{Scn1bb modulates neuronal function in vivo}

To identify in vivo roles of Scn 1 bb in nervous system function and development, we used a morpholino-based approach to knock-down Scn 1bb. We injected embryos with either a translation blocking morpholino targeting Scn1bb (Scn1bbMO) or a control morpholino (Scn1bbCTL). We first tested for roles in ion conduction, as expected for a subunit of voltage-gated sodium channel complexes. Similar to mammalian Scn1b, Scn1bb modulates the tetrodotoxin-sensitive $\mathrm{Na}^{+}$channel $\alpha$-subunit scn8aa (encoding Nav1.6a) when coexpressed in a heterologous system (supplemental Fig. 3, supplemental Tables 1 and 2, available at www.jneurosci.org as supplemental material). Whereas our survey of Scn1bb protein expression focused on non-neuronal cell types, we had also detected scn 1 bb mRNA in RB neurons (supplemental Fig. 2, available at www.jneurosci.org as supplemental material).

Accordingly, we first tested for in vivo effects on native currents. We recorded $\mathrm{Na}^{+}$currents in $\mathrm{RB}$ neurons, because these cells express both scn8aa and scn $1 b b$ mRNAs and are accessible to whole-cell recording methods (Ribera and Nüsslein-Volhard, 1998). RB neurons serve as primary mechanosensory neurons for 


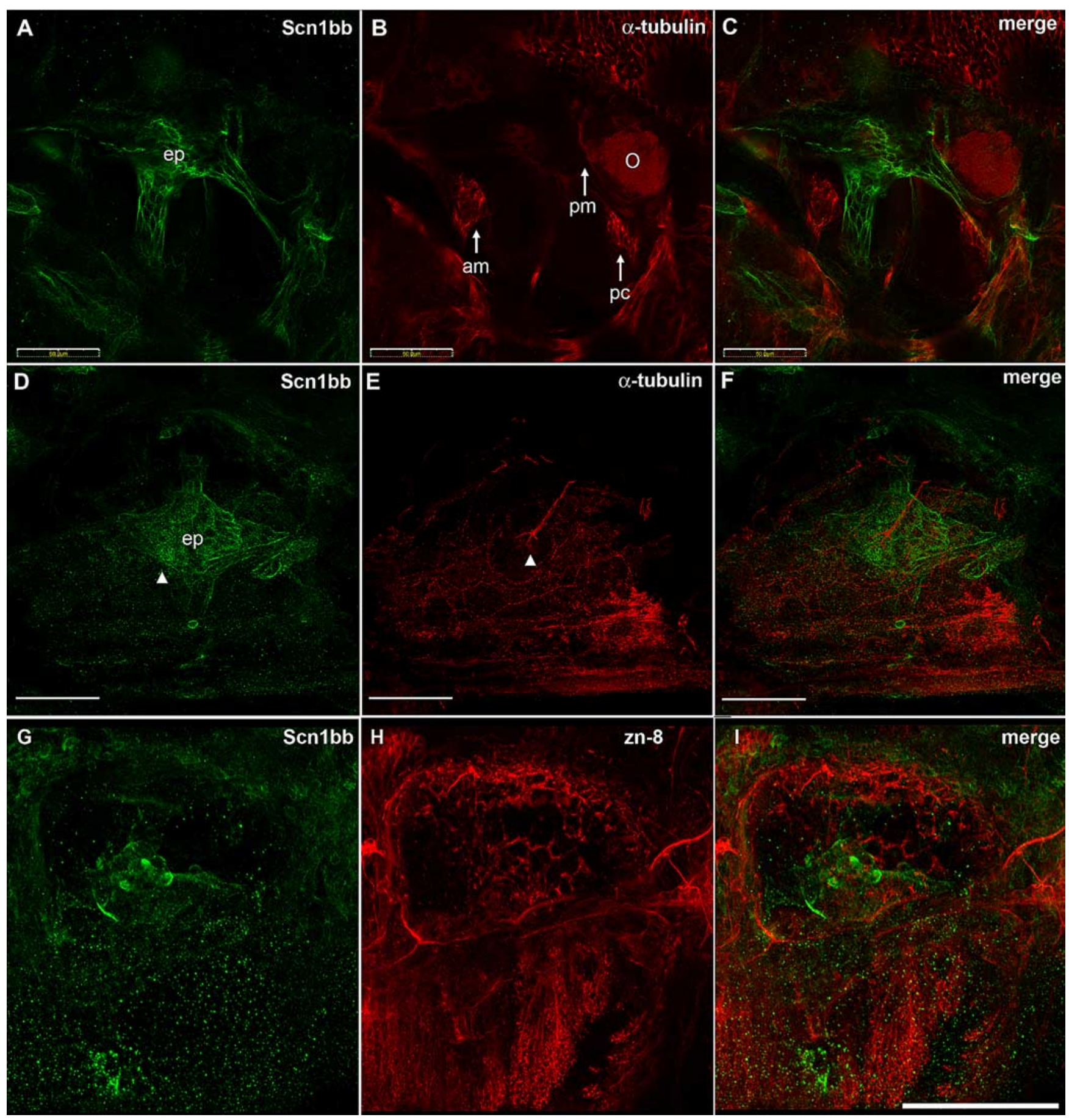

Figure 5. Scn $1 \mathrm{bb}$ is expressed in the semicircular canals of the inner ear. $\boldsymbol{A}$, Anti-Scn $1 \mathrm{bb}$ (green) labels the epithelial pillars (ep) of the semicircular canal in $5 \mathrm{dpf}$ fish. $\boldsymbol{B}$, Anti-acetylated $\alpha$-tubulin (red) labels the sensory patches found in inner ear ( 0 , otolith; am, anterior macula; pc, posterior crista; pm, posterior macula). C, Merged image shows that expression of Scn $1 \mathrm{bb}$ (green) and acetylated $\alpha$-tubulin (red) is nonoverlapping. $\boldsymbol{D}$, Anti-Scn $1 \mathrm{bb}$ labels the base of the otic neuromast (arrowhead) in addition to the epithelial pillars. E, Anti-acetylated $\alpha$-tubulin labels the kinocilia projecting from the otic neuromast (arrowhead). $\boldsymbol{F}$, The two expression domains are nonoverlapping. $\boldsymbol{G}$, Anti-Scn $1 \mathrm{bb}$ (green) labels the otic vesicle in $72 \mathrm{hpf}$ fish. $\boldsymbol{H}, \mathbf{Z n}-8$ (red). I, Merged image. Scale bars: $A-F, 50 \mu \mathrm{m} ; G-I, 100 \mu \mathrm{m}$.

the developing embryo before dorsal root ganglia develop (Clarke et al., 1984). In contrast to the dorsal root ganglia, RB somata reside within the CNS in the dorsal most aspect of the spinal cord. We found that $\mathrm{Na}^{+}$current peak amplitudes were significantly reduced in Scn1bb morphants compared with controls, consistent with effects observed for heterologously expressed subunits (Fig. 7A; supplemental Fig. 3, available at www. jneurosci.org as supplemental material).
The decrease in $\mathrm{RB} \mathrm{Na}^{+}$current amplitudes produced by Scnlbb knock-down raised the possibility that the behavior mediated by RB neurons, the touch response, would be defective in morphant embryos. We found that injection of the Scnlbb MO, but not the control MO, led to a significant reduction in touch sensitivity (Fig. $7 B$ ). These in vivo findings indicate that voltage-gated $\mathrm{Na}^{+}$ channel function in vivo shows an essential requirement for Scn1bb. 

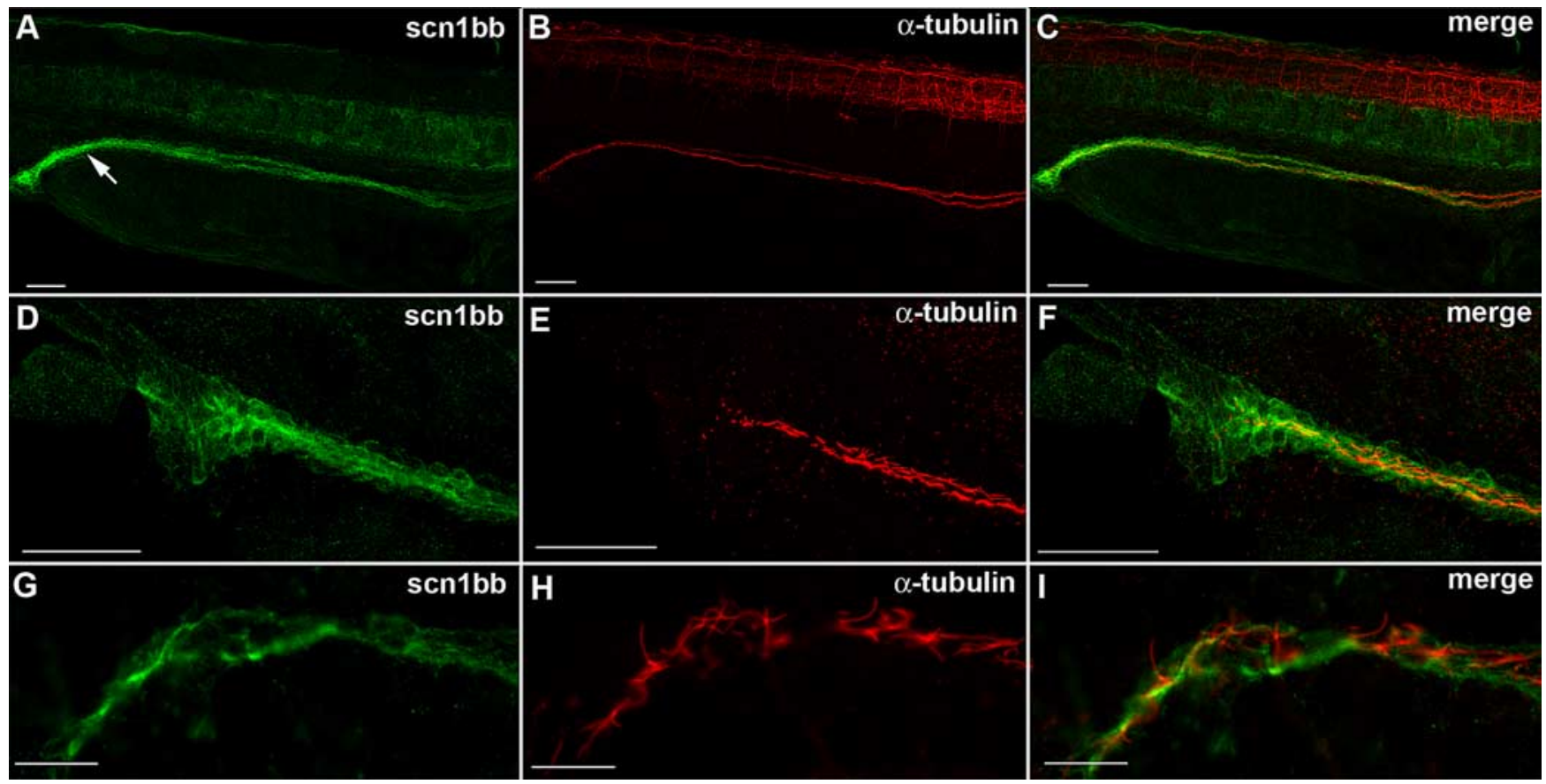

Figure 6. Scn1bb is expressed in the epithelial cells of the pronephric duct. $\boldsymbol{A}$, Anti-Scn $1 \mathrm{bb}$ (green) labeled the cells spanning the pronephric duct (arrow) in $28 \mathrm{hpf}$ fish. $\boldsymbol{B}$, Anti-acetylated $\alpha$-tubulin (red) labeled the cilia that line the pronephric duct. C, Anti-Scn $1 \mathrm{bb}$ (green) and anti-acetylated $\alpha$-tubulin (red) colabeled the pronephric duct. $\boldsymbol{D}$, Anti-Scn $1 \mathrm{bb}$ (green) labeled epithelial cells of the pronephric duct. $\boldsymbol{E}$, Anti-acetylated $\alpha$-tubulin (red) labeled the ciliated interior of the pronephric duct. $\boldsymbol{F}$, Expression of scn $1 \mathrm{bb}$ (green) and acetylated $\alpha$-tubulin (red) is nonoverlapping. $\boldsymbol{G}$, High magnification image of anti-Scn1bb positive (green) epithelial cells. $\boldsymbol{H}$, High magnification image of anti-acetylated $\alpha$-tubulin positive (red) cilia. $\boldsymbol{I}$, Merged image with expression of $S \mathrm{cn} 1 \mathrm{bb}$ (green) and acetylated $\alpha$-tubulin (red) nonoverlapping. Scale bars: $\mathbf{A}-\mathbf{F}, 50 \mu \mathrm{m} ; \mathbf{G}-\mathbf{I}, 10 \mu \mathrm{m}$.

A

$\mathrm{Na}+$ Current in Rohon-Bearc Cells In Scn1bb Morphants

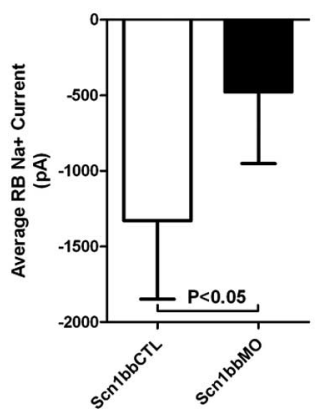

B

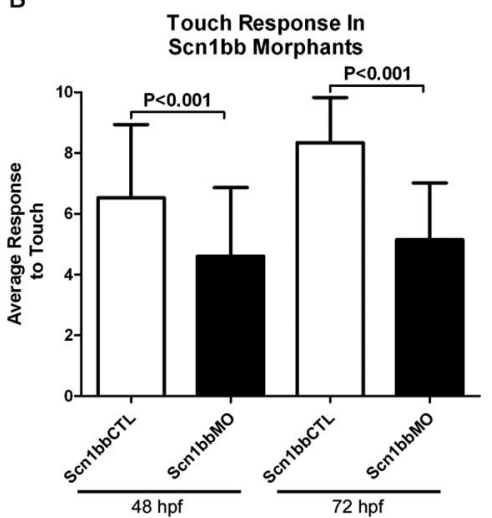

Figure 7. Embryos injected with $\mathrm{Scn} 1 \mathrm{bbMO}$ have reduced $\mathrm{Na}^{+}$current amplitudes in $\mathrm{RB}$ neurons and display touch insensitivity. $\boldsymbol{A}$, Peak $\mathrm{Na}^{+}$current in $\mathrm{RB}$ neurons average $-1329.5 \pm 518.7 \mathrm{pA}$ in embryos injected with $\operatorname{Scn} 1 \mathrm{bbCTL}(n=4)$, but only $-477.2 \pm 474.7$ in embryos injected with Scn1bbM0 ( $n=5 ; p<0.05$; Student's $t$ test). $\boldsymbol{B}$, At 48 hpf, embryos injected with $S \mathrm{cn} 1 \mathrm{bbM} 0$ had an average response to touch of $4.6 \pm 2.3(n=180)$, compared with an average response of $6.5 \pm 2.4(n=180)$ in embryos injected with Scn 1 bbCTL ( $p<$ 0.001; ANOVA). Similarly, $72 \mathrm{hpf}$ embryos injected with $\mathrm{Scn} 1 \mathrm{bb}$ had an average response to touch of $5.1 \pm 1.9(n=163)$ compared with an average response of $8.3 \pm 1.5(n=60)$ in embryos injected with Scn1bbCTL ( $p<0.001$; ANOVA).

\section{Knock-down of Scn 1 bb produces phenotypes associated with defective CAM function}

We examined Scn1bb morphant embryos for phenotypes that have previously been found when either $\mathrm{Na}^{+}$channel $\alpha$ - or $\beta$-subunits have been eliminated during developmental stages (Pineda et al., 2006; Brackenbury et al., 2008b). We first studied the consequences of Scn1bb knock-down on motor axon morphology because knock-down of the a $\mathrm{Na}^{+}$channel $\alpha$-subunit affects this phenotype. For these experiments we used the

$\mathrm{Tg}(\mathrm{Hb} 9: \mathrm{GFP})$ transgenic line that expresses GFP in motor neurons. At 72 hpf, motor axons branched more in Scn1bbMOinjected embryos than in control-injected embryos (Fig. 8A, $B$; $248 \pm 51$ motor axon branches for Scn 1 bbMO vs $171 \pm 31$ motor axon branches for Scn 1bbCTL; $p=0.0005$, Student's $t$ test), suggesting that $\mathrm{Scn} 1 \mathrm{bb}$ plays a role in motor axon branching in zebrafish embryos. Compared with results obtained by knockdown of the Nav1.6a $\alpha$-subunit, encoded by the scnsaa gene (Pineda et al., 2006), knock-down of Scn1bb produced similar but milder motor axon phenotypes.

On the basis of the Scn 1 bb expression pattern, we also examined the olfactory system and inner ear for possible defects on knock-down of Scn1bb. The olfactory nerve displayed defective morphology within the olfactory pit. In control embryos, a fasciculated olfactory nerve displayed strong acetylated $\alpha$-tubulin immunoreactivity as it exited the pit and entered the bulb (Fig. $8 C$ ). In contrast, acetylated $\alpha$-tubulin immunoreactivity revealed aberrant fasciculation within the pit of morphant embryos (Fig. $8 D$ ). Instead of the prominent fasciculated nerve evident at the point of exit from the pit, as in control embryos (Fig. 8C, star), morphant embryos displayed several acetylated $\alpha$-tubulin positive subdivisions of the nerve within the major compartment of the pit (Fig. $8 D$, stars). Compared with controls, the olfactory nerve of morphants had significantly increased branches within the pit $(6 \pm 2.28$ for ScnlbbMO versus $1.7 \pm 0.92$ for Scn1bbCTL; $p=0.0001$, Student's $t$ test). In the inner ear, there was an obvious increase in the number of hair cells in morphant embryos (Fig. $8 E, F$ ). On average, morphant embryos had $88 \pm$ 13 hair cells at $72 \mathrm{hpf}$, whereas control embryos had only $69 \pm 19$ hair cells $(p=0.005)$.

Overall, our data support the idea that $\mathrm{Na}^{+}$channel $\beta 1$ subunits play multiple important and diverse roles as members of 

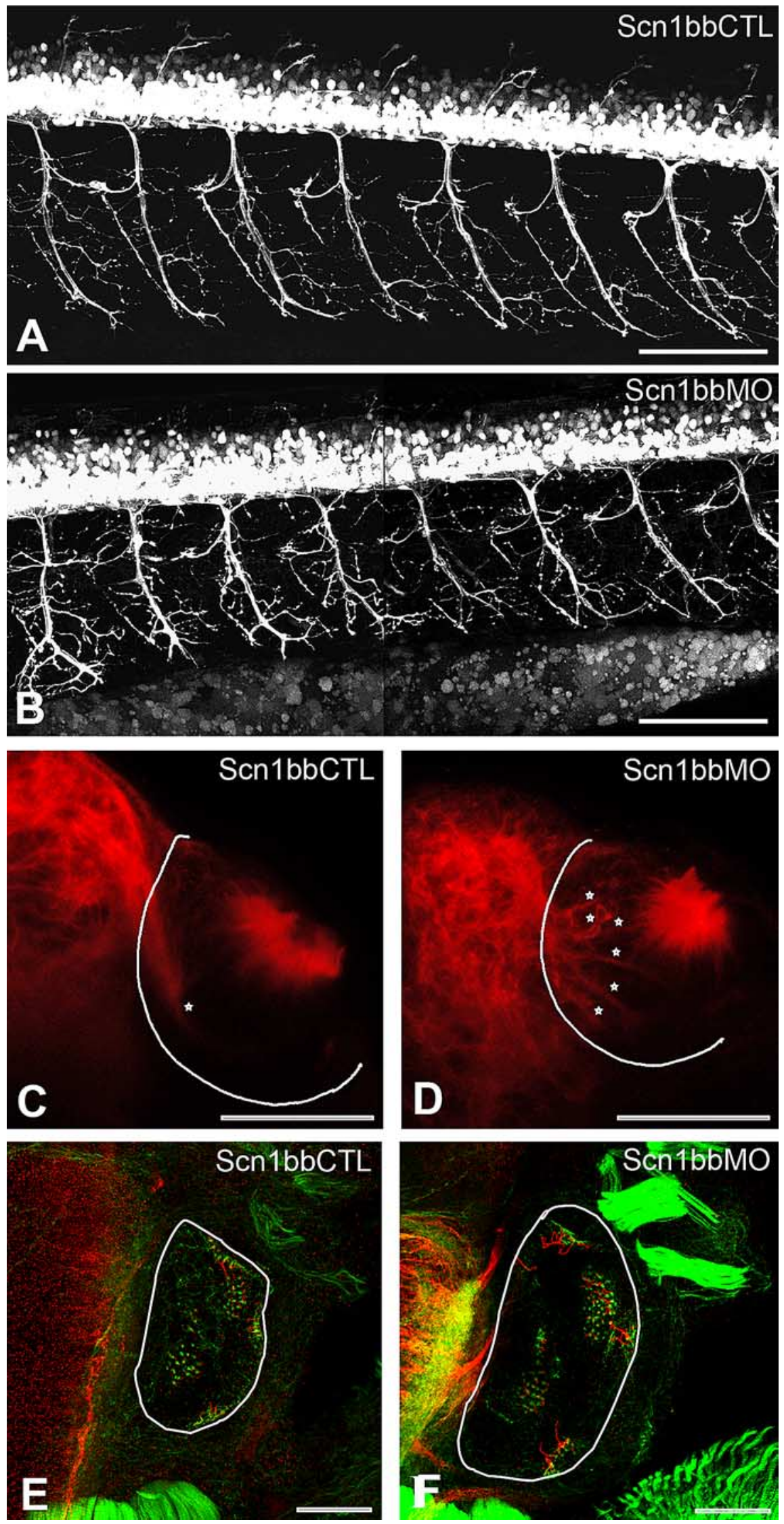

Figure 8. Scn1bbM0 leads to abnormal development of motor axons, the olfactory nerve, and hair cells. $\boldsymbol{A}, \boldsymbol{B}$, Lateral views of live $72 \mathrm{hpf} \mathrm{Tg}(\mathrm{Hb} 9: \mathrm{GFP})$ embryos injected with $\operatorname{Scn} 1 \mathrm{bbCTL}(\boldsymbol{A})$ or $\operatorname{Scn} 1 \mathrm{bbMO}(\boldsymbol{B})$; anterior is to the left, and dorsal is at the top. Scale bar, $100 \mu \mathrm{m}$. C, D, Abnormal fasciculation of the olfactory nerve (stars) within the olfactory pit (outlined in white) in $72 \mathrm{hpf}$ embryos injected with $\operatorname{Scn} 1 \mathrm{bbMO}(\boldsymbol{D})$ versus Scn1bbCTL (C). The olfactory nerve is visualized with an immunostain against ion channel complexes as well as CAMs, the latter reflecting a possible ion conduction independent function.

\section{Discussion}

In contrast to mammals, zebrafish express at least two $\beta 1$-subunit genes, scn1ba and $s c n 1 b b$. Our results inform about the evolutionary origins of the two zebrafish $s c n 1 b$ genes and identify potential novel roles for the newly discovered $s c n 1 b b$ gene.

Differential expression of scn $1 b a$ and $s c n 1 b b$ supports functional subdivision of the roles of an ancestral $S C N 1 B$ gene In mammals, a single $\beta 1$-subunit gene, $S C N 1 B$, exists that is expressed in a cell type and developmentally specific manner (Tong et al., 1993). In contrast, zebrafish has two identified $s c n 1 b$ orthologs, scn $1 b a$ (Fein et al., 2007) and scn $1 b b$ (this study), that are located on different chromosomes. A large number of mammalian genes are represented twice in the zebrafish genome as a result of a large scale genome wide duplication event that occurred during teleost evolution (Taylor et al., 2001). Several models propose that duplicated genes were more likely to be retained throughout evolution if they underwent subfunctionalization (Lynch and Force, 2000; Lynch et al., 2001; Van de Peer et al., 2001). The differential expression patterns of scn $1 b a$ (principally in excitable cells) and scn $1 b b$ (present in excitable and nonexcitable cells) supports functional subdivision of $S C N 1 B$ function in the teleost lineage.

\section{Shared functions of zebrafish \\ SCN1B paralogs}

Similar to Scn1ba, Scn1bb protein localizes to excitable cells (e.g., RB and other spinal cord neurons; supplemental Fig. 2, available at www.jneurosci.org as supplemental material). Previous work indicated that $\mathrm{Scn} 1$ ba plays a conventional ion channel associated function and modulates $\mathrm{Na}^{+}$currents (Fein et al., 2007). We found that $\mathrm{Scn} 1 \mathrm{bb}$ also modulates $\mathrm{Na}^{+}$currents. However, two interesting differences exist between the electrophysiological effects of the two duplicated zebrafish genes. First, a small but significant noninactivating $\mathrm{Na}^{+}$ current was observed in the presence of Scn1ba, while $\mathrm{Na}^{+}$current inactivated

\section{$\leftarrow$}

$\alpha$-acetylated tubulin (red). Scale bar, $50 \mu \mathrm{m} . \boldsymbol{E}, \boldsymbol{F}$, Hair cells within the otic vesicle (outlined in white) of $72 \mathrm{hpf}$ embryos injected with Scn 1 bbCTL $(\boldsymbol{E})$ or Scn1bbMO $(\boldsymbol{F})$ visualized with phalloidin (green) and $\alpha$ acetylated tubulin (red). Scale bar, $50 \mu \mathrm{m}$. 
completely in the presence of Scn1bb. Second, Scn1ba and Scnlbb had different effects on the extent and rate of recovery from inactivation. These findings add further support to the view that subdivision of an ancestral SCN1B gene function occurred in the teleost lineage. Of the two duplicated genes, $s c n 1 b b$ is the most similar to $S c n 1 b$ in terms of current modulation and the amino acid sequence of Scn 1 bb shares greater identity with $S c n 1 b$ than does Scn lba. We have proposed previously that differences in the $\beta$ strands, especially the presence of proline residues, of the Ig loop domain of Scn1ba may be responsible for its different observed effects on channel modulation (Fein et al., 2007).

\section{Novel functions of Scn1bb}

In addition to excitable cells, Scn1bb protein also localizes to several different types of nonexcitable cells including oligodendrocytes, Schwann cells, lateral line neuromasts, epithelial cells of the pronephros, cells of the olfactory epithelium and inner ear supporting cells. Similarly, in mammals, optic nerve astrocytes and Schwann cells express Scn1b (Oh and Waxman, 1994, 1995; Oh et al., 1997). Scn1bb distribution is reminiscent of that of the $\beta 2$-subunit of $\mathrm{Na}^{+} / \mathrm{K}^{+}$ATPase (AMOG) in excitable and nonexcitable cells (Xiao et al., 1999). AMOG functions both as a CAM involved in neuron-glia interactions and as a member of the $\mathrm{Na}^{+} / \mathrm{K}^{+}$ATPase ion transport complex (Müller-Husmann et al., 1993).

Although $\mathrm{Na}^{+}$currents have been recorded from immature oligodendrocyte precursors in culture (Glassmeier and Jeserich, 1995; Williamson et al., 1997; Bernard et al., 2001), $\mathrm{Na}^{+}$currents are not detected in oligodendrocytes recorded from identified glial cells in hippocampal slices (Sontheimer and Waxman, 1993), suggesting that $\mathrm{Na}^{+}$channel $\alpha$-subunits are not expressed in mature, myelinating oligodendrocytes in vivo. A recent report suggests two classes of spiking and nonspiking oligodendrocyte precursor cells, resulting from differential expression of TTX-S $\mathrm{Na}^{+}$currents (Káradóttir et al., 2008). Oligodendrocyte precursor cells lose $\mathrm{Na}^{+}$current expression as they mature, such that no currents are detected in myelinating oligodendrocytes (Sontheimer et al., 1989; Káradóttir et al., 2008). Costaining of optic nerve sections with anti-Scn 1 bb and pan- $\mathrm{Na}^{+}$channel $\alpha$-subunit antibodies showed the absence of $\mathrm{Na}^{+}$channel $\alpha$-subunits but the presence of Scn $1 b b$ in the myelin sheath. These results provide evidence that $\mathrm{Scn} 1 \mathrm{bb}$ is expressed in the myelin in the absence of the ion-conducting pore. As discussed further below, we propose that Scn1bb functions in myelin as a CAM involved in neuronglia interactions.

In mice, deletion of Scn $1 \mathrm{~b}$ in vivo results in everted paranodal loops in a subpopulation of CNS nodes of Ranvier (Chen et al., 2004), disrupted cerebellar granule neuron migration, and aberrant fasciculation of corticospinal tract axons (Brackenbury et al., 2008b). These data support a role for Scn1b in CAM complexes involved in forming septate-like junctions linking the myelin sheath to the axonal membrane, regulating growth cone migration, and mediating axonal fasciculation (Brackenbury et al., 2008a). In support of this idea, we found that knock-down of Scn 1 bb led to defects in the extent of branching of motor neuron axons (Fig. 8). Further, we did not detect Scn1bb protein in the motor neurons themselves but rather in Schwann cells that ensheath peripheral motor axons. These results suggest that Scn $1 \mathrm{bb}$ influences motor axon morphology noncell autonomously. Similarly, previous studies revealed a noncell autonomous role for the sodium channel $\alpha$-subunit in regulation of motor axon development (Pineda et al., 2006).

In the olfactory epithelium, supporting cells envelop OSNs and adhere to each other via a complex that includes adherence junctions and desmosomes (Hansen and Zielinski, 2005; Hegg and Lucero, 2006). We detected Scn 1 bb in these supporting cells (Fig. 3F). Knock-down of Scn 1 bb produced defects in the morphology of the olfactory nerve as it formed in the olfactory pit. The defasiculated appearance of the olfactory nerve in Scn1bb morphant embryos (Fig. 8) further supports a CAM role for the subunit in supporting cells of the olfactory epithelium. Inner ear supporting cells also express Scn $1 \mathrm{bb}$. We found that knock-down of Scn 1 bb led to a $\sim 30 \%$ increase in hair cell number (Fig. 8). Whereas the underlying mechanism is not obvious, one possibility is that lack of Scn 1 bb interferes with apposition of inner ear cells that is required for proper Notch signaling and specification of the appropriate number of hair cells (Kelley, 2003; Kiernan et al., 2005). Because reductions in electrical activity are not thought to be sufficient to alter neuromast patterning in the zebrafish lateral line (Grant et al., 2005), it is possible that Scn1bbmediated cell adhesive interactions and not Scnlbb-mediated modulation of channel activity is responsible for the observed phenotype. Together, our findings support a CAM role for Scn 1 bb in supporting and epithelial cells in the absence of the $\mathrm{Na}^{+}$channel ion-conducting pore.

\section{$\mathrm{Na}^{+}$channel $\beta 1$-subunits are multifunctional}

In mammals, $S c n 1 b$ plays an essential role during development of the mammalian CNS in vivo (Brackenbury et al., 2008b). The cerebella of Scn1b null mice exhibit disorganized, defasciculated parallel fibers as well as abnormal cerebellar granule neuron axonal patterning through the molecular layer into the internal granule cell layer. These effects are similar to those observed in mice lacking the CAM contactin (Berglund et al., 1999). In the corticospinal tracts of $S c n 1 b$ null mice, we observed reduced fasciculation at the pyramidal decussation, with axons projecting laterally from the dorsal column, beyond the pyramidal decussation. These effects are also consistent with disrupted CAM interactions. In the present study, we report increased axonal branching of zebrafish spinal motor neurons in the absence of Scn 1 bb. Further, similar to macho, alligator, and steifftier mutants, Scn 1 bb morphant fish have significantly reduced touch sensitivity as well as reduced $\mathrm{Na}^{+}$currents in $\mathrm{RB}$ neurons. Thus, we propose that Scn 1 bb serves multiple functions in the developing zebrafish nervous system: first, to regulate electrical excitability via changes in $\mathrm{Na}^{+}$current, and second, to modulate neuronal pathfinding through cell adhesive interactions.

\section{References}

Berglund EO, Murai KK, Fredette B, Sekerková G, Marturano B, Weber L, Mugnaini E, Ranscht B (1999) Ataxia and abnormal cerebellar microorganization in mice with ablated contactin gene expression. Neuron 24:739-750.

Bernard F, Bossu JL, Gaillard S (2001) Identification of living oligodendrocyte developmental stages by fractal analysis of cell morphology. J Neurosci Res 65:439-445.

Brackenbury WJ, Isom LL (2008) Voltage-gated Na+ channels: Potential for $\beta$-subunits as therapeutic targets. Expert Opin Ther Targets 12:1191-1203.

Brackenbury WJ, Djamgoz MB, Isom LL (2008a) An emerging role for voltage-gated $\mathrm{Na}+$ channels in cellular migration: regulation of central nervous system development and potentiation of invasive cancers. Neuroscientist. Advance online publication. Retrieved November 3, 2008. doi:10.1177/1073858408320293

Brackenbury WJ, Davis TH, Chen C, Slat EA, Detrow MJ, Dickendesher TL, Ranscht B, Isom LL (2008b) Voltage-gated Na + channel betal subunitmediated neurite outgrowth requires Fyn kinase and contributes to postnatal CNS development in vivo. J Neurosci 28:3246-3256.

Catterall WA (2000) From ionic currents to molecular mechanisms: the 
structure and function of voltage-gated sodium channels. Neuron 26:13-25.

Chen C, Westenbroek RE, Xu X, Edwards CA, Sorenson DR, Chen Y, McEwen DP, O'Malley HA, Bharucha V, Meadows LS, Knudsen GA, Vilaythong A, Noebels JL, Saunders TL, Scheuer T, Shrager P, Catterall WA, Isom LL (2004) Mice lacking sodium channel betal subunits display defects in neuronal excitability, sodium channel expression, and nodal architecture. J Neurosci 24:4030-4042.

Chopra SS, Watanabe H, Zhong TP, Roden DM (2007) Molecular cloning and analysis of zebrafish voltage-gated sodium channel beta subunit genes: Implications for the evolution of electrical signaling in vertebrates. BMC Evol Biol 7:113.

Clarke JD, Hayes BP, Hunt SP, Roberts A (1984) Sensory physiology, anatomy and immunohistochemistry of Rohon-Beard neurones in embryos of Xenopus laevis. J Physiol 348:511-525.

Davis TH, Chen C, Isom LL (2004) Sodium channel $\beta 1$ subunits promote neurite outgrowth in cerebellar granule neurons. J Biol Chem 279:51424-51432.

Diss JK, Fraser SP, Djamgoz MB (2004) Voltage-gated Na + channels: multiplicity of expression, plasticity, functional implications and pathophysiological aspects. Eur Biophys J 33:180-193.

Dolmetsch R (2003) Excitation-transcription coupling: signaling by ion channels to the nucleus. Sci STKE 2003:PE4.

Drummond I (2003) Making a zebrafish kidney: a tale of two tubes. Trends Cell Biol 13:357-365.

Drummond IA (2005) Kidney development and disease in the zebrafish. J Am Soc Nephrol 16:299-304.

Drummond IA, Majumdar A, Hentschel H, Elger M, Solnica-Krezel L, Schier AF, Neuhauss SC, Stemple DL, Zwartkruis F, Rangini Z, Driever W, Fishman MC (1998) Early development of the zebrafish pronephros and analysis of mutations affecting pronephric function. Development 125:4655-4667.

Fashena D, Westerfield M (1999) Secondary motoneuron axons localize DM-GRASP on their fasciculated segments. J Comp Neurol 406:415-424.

Fein AJ, Meadows LS, Chen C, Slat EA, Isom LL (2007) Cloning and expression of a zebrafish SCN1B ortholog and identification of a species-specific splice variant. BMC Genomics 8:226.

Flanagan-Steet H, Fox MA, Meyer D, Sanes JR (2005) Neuromuscular synapses can form in vivo by incorporation of initially aneural postsynaptic specializations. Development 132:4471-4481.

Girault JA, Peles E (2002) Development of nodes of Ranvier. Curr Opin Neurobiol 12:476-485.

Glassmeier G, Jeserich G (1995) Changes in ion channel expression during in vitro differentiation of trout oligodendrocyte precursor cells. Glia 15:83-93.

Gomez-Ospina N, Tsuruta F, Barreto-Chang O, Hu L, Dolmetsch R (2006) The $\mathrm{C}$ terminus of the L-type voltage-gated calcium channel $\mathrm{Ca}(\mathrm{V}) 1.2$ encodes a transcription factor. Cell 127:591-606.

Grant KA, Raible DW, Piotrowski T (2005) Regulation of latent sensory hair cell precursors by glia in the zebrafish lateral line. Neuron 45:69-80.

Hansen A, Zeiske E (1993) Development of the olfactory organ in the zebrafish, Brachydanio rerio. J Comp Neurol 333:289-300.

Hansen A, Zielinski BS (2005) Diversity in the olfactory epithelium of bony fishes: development, lamellar arrangement, sensory neuron cell types and transduction components. J Neurocytol 34:183-208.

Hegg CC, Lucero MT (2006) Purinergic receptor antagonists inhibit odorant-induced heat shock protein 25 induction in mouse olfactory epithelium. Glia 53:182-190.

Hegle AP, Marble DD, Wilson GF (2006) A voltage-driven switch for ionindependent signaling by ether-a-go-go K + channels. Proc Natl Acad Sci U S A 103:2886-2891.

Isom LL (2001) Sodium channel $\beta$ subunits: anything but auxiliary. Neuroscientist 7:42-54.

Isom LL, Catterall WA (1996) $\mathrm{Na}^{+}$channel subunits and Ig domains. Nature 383:307-308.

Isom LL, De Jongh KS, Patton DE, Reber BF, Offord J, Charbonneau H, Walsh K, Goldin AL, Catterall WA (1992) Primary structure and functional expression of the $\beta 1$ subunit of the rat brain sodium channel. Science 256:839-842.

Isom LL, Scheuer T, Brownstein AB, Ragsdale DS, Murphy BJ, Catterall WA (1995) Functional co-expression of the $\beta 1$ and type IIA $\alpha$ subunits of sodium channels in a mammalian cell line. J Biol Chem 270:3306-3312.
Johnson D, Montpetit ML, Stocker PJ, Bennett ES (2004) The sialic acid component of the betal subunit modulates voltage-gated sodium channel function. J Biol Chem 279:44303-44310.

Kaczmarek LK (2006) Non-conducting functions of voltage-gated ion channels. Nat Rev Neurosci 7:761-771.

Káradóttir R, Hamilton NB, Bakiri Y, Attwell D (2008) Spiking and nonspiking classes of oligodendrocyte precursor glia in CNS white matter. Nat Neurosci 11:450-456.

Kazarinova-Noyes K, Shrager P (2002) Molecular constituents of the node of Ranvier. Mol Neurobiol 26:167-182.

Kazarinova-Noyes K, Malhotra JD, McEwen DP, Mattei LN, Berglund EO, Ranscht B, Levinson SR, Schachner M, Shrager P, Isom LL, Xiao ZC (2001) Contactin associates with $\mathrm{Na}^{+}$channels and increases their functional expression. J Neurosci 21:7517-7525.

Kelley MW (2003) Cell adhesion molecules during inner ear and hair cell development, including notch and its ligands. Curr Top Dev Biol 57:321-356.

Kiernan AE, Cordes R, Kopan R, Gossler A, Gridley T (2005) The Notch ligands DLL1 and JAG2 act synergistically to regulate hair cell development in the mammalian inner ear. Development 132:4353-4362.

Kim DY, Ingano LA, Carey BW, Pettingell WP, Kovacs DM (2005) Presenilin/gamma-secretase-mediated cleavage of the voltage-gated sodium channel beta 2 subunit regulates cell adhesion and migration. J Biol Chem 280:23251-23261.

Kim DY, Carey BW, Wang H, Ingano LA, Binshtok AM, Wertz MH, Pettingell WH, He P, Lee VM, Woolf CJ, Kovacs DM (2007) BACE1 regulates voltage-gated sodium channels and neuronal activity. Nat Cell Biol.

Kucenas S, Takada N, Park HC, Woodruff E, Broadie K, Appel B (2008) CNS-derived glia ensheath peripheral nerves and mediate motor root development. Nat Neurosci 11:143-151.

Levitan IB (2006) Signaling protein complexes associated with neuronal ion channels. Nat Neurosci 9:305-310.

Lewis KE, Eisen JS (2003) From cells to circuits: development of the zebrafish spinal cord. Prog Neurobiol 69:419-449.

López-Schier H, Starr CJ, Kappler JA, Kollmar R, Hudspeth AJ (2004) Directional cell migration establishes the axes of planar polarity in the posterior lateral-line organ of the zebrafish. Dev Cell 7:401-412.

Lynch M, Force A (2000) The probability of duplicate gene preservation by subfunctionalization. Genetics 154:459-473.

Lynch M, O'Hely M, Walsh B, Force A (2001) The probability of preservation of a newly arisen gene duplicate. Genetics 159:1789-1804.

MacLean JN, Zhang Y, Johnson BR, Harris-Warrick RM (2003) Activityindependent homeostasis in rhythmically active neurons. Neuron 37:109-120.

MacLean JN, Zhang Y, Goeritz ML, Casey R, Oliva R, Guckenheimer J, Harris-Warrick RM (2005) Activity-independent coregulation of IA and Ih in rhythmically active neurons. J Neurophysiol 94:3601-3617.

Malhotra JD, Kazen-Gillespie K, Hortsch M, Isom LL (2000) Sodium channel $\beta$ subunits mediate homophilic cell adhesion and recruit ankyrin to points of cell-cell contact. J Biol Chem 275:11383-11388.

Malhotra JD, Koopmann MC, Kazen-Gillespie KA, Fettman N, Hortsch M, Isom LL (2002) Structural requirements for interaction of sodium channel $\beta 1$ subunits with ankyrin. J Biol Chem 277:26681-26688.

Malhotra JD, Thyagarajan V, Chen C, Isom LL (2004) Tyrosinephosphorylated and nonphosphorylated sodium channel betal subunits are differentially localized in cardiac myocytes. J Biol Chem 279:40748-40754.

McCormick KA, Isom LL, Ragsdale D, Smith D, Scheuer T, Catterall WA (1998) Molecular determinants of $\mathrm{Na}^{+}$channel function in the extracellular domain of the $\beta 1$ subunit. J Biol Chem 273:3954-3962.

McEwen DP, Isom LL (2004) Heterophilic interactions of sodium channel beta 1 subunits with axonal and glial cell adhesion molecules. J Biol Chem 279:52744-52752.

McEwen DP, Meadows LS, Chen C, Thyagarajan V, Isom LL (2004) Sodium channel $\beta 1$ subunit-mediated modulation of Nav1.2 currents and cell surface density is dependent on interactions with contactin and ankyrin. J Biol Chem 279:16044-16049.

Müller-Husmann G, Gloor S, Schachner M (1993) Functional characterization of beta isoforms of murine $\mathrm{Na}, \mathrm{K}$-ATPase. The adhesion molecule on glia (AMOG/beta 2), but not beta 1, promotes neurite outgrowth. J Biol Chem 268:26260-26267. 
Nicolson T (2005) The genetics of hearing and balance in zebrafish. Annu Rev Genet 39:9-22.

Oh Y, Waxman SG (1994) The beta 1 subunit mRNA of the rat brain $\mathrm{Na}+$ channel is expressed in glial cells. Proc Natl Acad Sci U S A 91:9985-9989.

Oh Y, Waxman SG (1995) Differential Na + channel beta 1 subunit mRNA expression in stellate and flat astrocytes cultured from rat cortex and cerebellum: a combined in situ hybridization and immunocytochemistry study. Glia 13:166-173.

Oh Y, Lee YJ, Waxman SG (1997) Regulation of $\mathrm{Na}^{+}$channel $\beta 1$ and $\beta 2$ subunit mRNA levels in cultured rat astrocytes. Neurosci Lett 234:107-110.

Pineda RH, Heiser RA, Ribera AB (2005) Developmental, molecular, and genetic dissection of INa in vivo in embryonic zebrafish sensory neurons. J Neurophysiol 93:3582-3593.

Pineda RH, Svoboda KR, Wright MA, Taylor AD, Novak AE, Gamse JT, Eisen JS, Ribera AB (2006) Knockdown of Nav1.6a Na+ channels affects zebrafish motoneuron development. Development 133:3827-3836.

Postlethwait JH (2007) The zebrafish genome in context: ohnologs gone missing. J Exp Zoolog B Mol Dev Evol 308:563-577.

Raible DW, Kruse GJ (2000) Organization of the lateral line system in embryonic zebrafish. J Comp Neurol 421:189-198.

Ribera AB, Nüsslein-Volhard C (1998) Zebrafish touch-insensitive mutants reveal an essential role for the developmental regulation of sodium currents. J Neurosci 18:9181-9191.

Sapède D, Gompel N, Dambly-Chaudiere C, Ghysen A (2002) Cell migration in the postembryonic development of the fish lateral line. Development 129:605-615.

Shapiro L, Doyle JP, Hensley P, Colman DR, Hendrikson WA (1996) Crystal structure of the extracellular domain from $\mathrm{P}_{\mathrm{o}}$, the major structural protein of peripheral nerve myelin. Neuron 17:435-449.

Sontheimer H, Waxman SG (1993) Expression of voltage-activated ion channels by astrocytes and oligodendrocytes in the hippocampal slice. J Neurophysiol 70:1863-1873.

Sontheimer H, Trotter J, Schachner M, Kettenmann H (1989) Channel expression correlates with differentiation stage during the development of oligodendrocytes from their precursor cells in culture. Neuron 2:1135-1145

Srinivasan J, Schachner M, Catterall WA (1998) Interaction of voltage- gated sodium channels with the extracellular matrix molecules tenascin- $C$ and tenascin-R. Proc Natl Acad Sci U S A 95:15753-15757.

Taylor JS, Van de Peer Y, Braasch I, Meyer A (2001) Comparative genomics provides evidence for an ancient genome duplication event in fish. Philos Trans R Soc Lond B Biol Sci 356:1661-1679.

Tong J, Potts JF, Rochelle JM, Seldin MF, Agnew WS (1993) A single B1 subunit mapped to mouse chromosome 7 may be a common component of $\mathrm{Na}$ channel isoforms from brain, skeletal, muscle and heart. Biochem Biophys Res Commun 195:679-685.

Tsujikawa M, Malicki J (2004) Intraflagellar transport genes are essential for differentiation and survival of vertebrate sensory neurons. Neuron 42:703-716.

Van de Peer Y, Taylor JS, Braasch I, Meyer A (2001) The ghost of selection past: rates of evolution and functional divergence of anciently duplicated genes. J Mol Evol 53:436-446.

Voas MG, Lyons DA, Naylor SG, Arana N, Rasband MN, Talbot WS (2007) alpha II-Spectrin is essential for assembly of the nodes of Ranvier in myelinated axons. Curr Biol 17:562-568.

Westerfield M (1995) The zebrafish book: a guide for the laboratory use of zebrafish (Brachydanio rerio). Eugene, OR: University of Oregon.

Whitfield TT (2005) Lateral line: precocious phenotypes and planar polarity. Curr Biol 15:R67-R70.

Williamson AV, Compston DA, Randall AD (1997) Analysis of the ion channel complement of the rat oligodendrocyte progenitor in a commonly studied in vitro preparation. Eur J Neurosci 9:706-720.

Wong HK, Sakurai T, Oyama F, Kaneko K, Wada K, Miyazaki H, Kurosawa M, De Strooper B, Saftig P, Nukina N (2005) beta subunits of voltagegated sodium channels are novel substrates of BACE1 and gammasecretase. J Biol Chem 280:23009-230.17

Woods IG, Wilson C, Friedlander B, Chang P, Reyes DK, Nix R, Kelly PD, Chu F, Postlethwait JH, Talbot WS (2005) The zebrafish gene map defines ancestral vertebrate chromosomes. Genome Res 15:1307-1314.

Woods IG, Lyons DA, Voas MG, Pogoda HM, Talbot WS (2006) nsf is essential for organization of myelinated axons in zebrafish. Curr Biol $16: 636-648$.

Xiao ZC, Ragsdale DS, Malhorta JD, Mattei LN, Braun PE, Schachner M, Isom LL (1999) Tenascin- $\mathrm{R}$ is a functional modulator of sodium channel $\beta$ subunits. J Biol Chem 274:26511-26517. 